University of Wollongong

Research Online

Australian Institute for Innovative Materials -

Papers

Australian Institute for Innovative Materials

$1-1-2018$

\title{
Tuning the structure of three dimensional nanostructured molybdenum disulfide/nitrogen-doped carbon composite for high lithium storage
}

\author{
Yunfeng Chao \\ University of Wollongong, yc682@uowmail.edu.au \\ Yu Ge \\ University of Wollongong, yg711@uowmail.edu.au \\ Yong Zhao \\ University of Wollongong, yz705@uowmail.edu.au \\ Jicheng Jiang \\ University of Wollongong, jj325@uowmail.edu.au \\ Caiyun Wang \\ University of Wollongong, caiyun@uow.edu.au
}

See next page for additional authors

Follow this and additional works at: https://ro.uow.edu.au/aiimpapers

Part of the Engineering Commons, and the Physical Sciences and Mathematics Commons

Research Online is the open access institutional repository for the University of Wollongong. For further information contact the UOW Library: research-pubs@uow.edu.au 


\title{
Tuning the structure of three dimensional nanostructured molybdenum disulfide/ nitrogen-doped carbon composite for high lithium storage
}

\author{
Abstract \\ Molybdenum disulfide/nitrogen-doped carbon nanocomposite can afford high capacity, good rate \\ capability and cycling stability in lithium ion batteries owing to the synergistic effect from these two \\ components. Structure of the material has a great impact on the performance as well. In this work, MoS2/ \\ nitrogen-doped carbon (MoS2/C) composites have been developed by manipulating the nano-featured \\ polypyrrole templates to guide and confine their growth. They are formed via a simple hydrothermal \\ process combined with a subsequent annealing process. The MoS2/nitrogen-doped carbon nanotubes \\ (MoS2/CNT) composite with $76 \%$ of MoS2 exhibits an excellent performance including a high capacity of \\ $1232 \mathrm{mAh} \mathrm{g}-1$ at a current density of $0.1 \mathrm{~A} \mathrm{~g}-1$, outstanding rate capability (947 mAh g-1 at $2 \mathrm{~A} \mathrm{~g}-1$ ), \\ and good cycling stability with $754 \mathrm{mAh} \mathrm{g-1}$ retained over 1000 charge/discharge cycles at a high current \\ density of $1 \mathrm{~A} \mathrm{~g}-1$. This performance is much better than that MoS2/nitrogen-doped carbon \\ nanoparticles (MoS2/CNP) composite. This work demonstrates the importance of introducing three- \\ dimensional nanostructures in electrode materials to improve their electrochemical performance. \\ Disciplines \\ Engineering | Physical Sciences and Mathematics

\section{Publication Details} \\ Chao, Y., Ge, Y., Zhao, Y., Jiang, J., Wang, C., Qin, C., Vijayakumar, A., Yu, C. \& Wallace, G. G. (2018). Tuning \\ the structure of three dimensional nanostructured molybdenum disulfide/nitrogen-doped carbon \\ composite for high lithium storage. Electrochimica Acta, 291 197-205.

\section{Authors} \\ Yunfeng Chao, Yu Ge, Yong Zhao, Jicheng Jiang, Caiyun Wang, Chunyan Qin, Amruthalakshmi \\ Vijayakumar, Changchun Yu, and Gordon G. Wallace
}




\title{
Tuning the structure of three dimensional nanostructured
}

\section{molybdenum disulfide/nitrogen-doped carbon composite for high}

\section{lithium storage}

Yunfeng Chao ${ }^{\mathrm{a}}$, Yu Ge ${ }^{\mathrm{a}}$, Yong Zhao ${ }^{\mathrm{a}}$, Jicheng Jiang ${ }^{\mathrm{b}}$, Caiyun Wang ${ }^{\mathrm{a}, *}$, Chunyan Qin $^{\mathrm{a}}$, Amruthalakshmi Vijayakumar ${ }^{\mathrm{a}}$, Changchun $\mathrm{Yu}^{\mathrm{a}}$, and Gordon G. Wallace ${ }^{\mathrm{a}, *}$

${ }^{a}$ ARC Centre of Excellence for Electromaterials Science, Intelligent Polymer Research Institute, AIIM Facility, University of Wollongong, North Wollongong, NSW 2500, Australia.

${ }^{\mathrm{b}}$ Institute for Superconducting and Electronic Materials, AIIM Facility, University of Wollongong, North Wollongong, NSW 2500, Australia.

E-mail: caiyun@uow.edu.au (C.W.), gwallace@uow.edu.au (G. G. W.)

\begin{abstract}
Molybdenum disulfide/nitrogen-doped carbon nanocomposite can afford high capacity, good rate capability and cycling stability in lithium ion batteries owing to the synergistic effect from these two components. The structure of this material has a great impact on the performance as well. In this work, $\mathrm{MoS}_{2} /$ nitrogen-doped carbon $\left(\mathrm{MoS}_{2} / \mathrm{C}\right)$ composites have been developed by manipulating the nano-featured polypyrrole templates to guide and confine their growth. They are formed via a simple hydrothermal process combined with a subsequent annealing process. The $\mathrm{MoS}_{2} /$ nitrogen-doped carbon nanotubes $\left(\mathrm{MoS}_{2} / \mathrm{CNT}\right)$ composite with $75 \%$ of $\mathrm{MoS}_{2}$ exhibits an excellent performance including a high capacity of $1232 \mathrm{mAh} \mathrm{g}^{-1}$ at a current density of $0.1 \mathrm{~A}$
\end{abstract}


$\mathrm{g}^{-1}$, outstanding rate capability (947 $\mathrm{mAh} \mathrm{g}^{-1}$ at $\left.2 \mathrm{~A} \mathrm{~g}^{-1}\right)$, and good cycling stability with 754 $\mathrm{mAh} \mathrm{g}^{-1}$ retained over 1,000 charge/discharge cycles at a high current density of $1 \mathrm{~A} \mathrm{~g}^{-1}$. This performance is much better than the $\mathrm{MoS}_{2} /$ nitrogen-doped carbon nanoparticles $\left(\mathrm{MoS}_{2} / \mathrm{CNP}\right)$ composite. This work demonstrates the importance of introducing three-dimensional nanostructures in electrode materials to improve their electrochemical performance.

Keywords: Nitrogen-doped carbon; Two-dimensional material; $\mathrm{MoS}_{2}$; Lithium-ion battery; Tubular nanostructure

\section{Introduction}

The rapid development of daily used personalized electronic devices such as cellphones, smart watches and laptops, calls for high performance lithium-ion batteries [1]. As a representative for two-dimensional (2D) transition metal dichalcogenides (TMDs) materials, molybdenum disulfide $\left(\mathrm{MoS}_{2}\right)$ is recognized as a promising alternative anode material due to its high theoretical capacity of $670 \mathrm{mAh} \mathrm{g}^{-1}$ [2-4]. Its intrinsic large interlayer distance $(0.62 \mathrm{~nm})$ and high surface area facilitate easy insertion of lithium ions and easy access of electrolyte [5]. However, $\mathrm{MoS}_{2}$ nanosheets suffer from low conductivity and aggregation as well as volume changes during the repeated intercalation/deintercalation of $\mathrm{Li}$ ions. All these lead to poor rate capability and poor cycling stability [6-9]. In order to overcome these drawbacks, two main effective approaches are applied: incorporation with conductive carbon materials as supports and creation of three-dimensional (3D) structures [6-9]. Introducing carbon materials can increase the conductivity as well as hinder the restacking problem of $\mathrm{MoS}_{2}[7,10,11]$. A 3D structure can offer the advantages of shortened ion diffusion path, increased surface area, and accommodating volume changes as well [12]. 
Among various carbon materials, nitrogen-doped carbon has attracted much attention owing to its merits of affording sufficient active sites, enhanced surface wettability, and high electrical conductivity $[13,14]$. The incorporation of heteroatom nitrogen into carbon creates a disordered structure with numerous defects that benefits lithium storage $[15,16]$. Combining nanostructured nitrogen-doped carbon and $\mathrm{MoS}_{2}$ afford better electrochemical performance by harnessing their inherent merits. The nitrogen-doped carbon acts as the conductive component in the composite; thus improving the rate capability and providing additional capacity as well. The 3D nanostructure can also buffer the volume changes of $\mathrm{MoS}_{2}$ during the charge/discharge process and suppress the restacking problems thus achieving long cycle life. The nanostructured $\mathrm{MoS}_{2} / \mathrm{C}$ composite has demonstrated excellent electrochemical properties in lithium batteries [17, 18]. For example, a high specific capacity of $947 \mathrm{mAh} \mathrm{g}^{-1}$ at $2 \mathrm{~A} \mathrm{~g}^{-1}$ was delivered by the roselike $\mathrm{MoS}_{2} /$ nitrogen-containing carbon/graphene hybrids [6], which was fabricated by hydrothermally growing $\mathrm{MoS}_{2}$ on PPy coated GO nanosheets in combination with a calcination process at 800 ${ }^{\circ} \mathrm{C}$. Using $\mathrm{Fe}_{2} \mathrm{O}_{3}$ nanocubes as templates, the nitrogen-doped carbon@ $\mathrm{MoS}_{2}$ nanoboxes composite [19] was prepared through the carbonization process of polydopamine, etching of templates and solvothermal growth of ultrathin $\mathrm{MoS}_{2}$ nanosheets; this material delivered a capacity of $689 \mathrm{mAh} \mathrm{g}^{-1}$ at a current density of $2 \mathrm{~A} \mathrm{~g}^{-1}$.

Nitrogen-doped carbon can be produced via chemical vapour deposition, thermal annealing, plasma treatment and the arc-discharge method $[13,20]$. Using polypyrrole (PPy) to produce nitrogen-doped carbon via a carbonization process has attracted attention because of its ease of processability, the controllable nano-scaled features such as nanoparticles, nanofibres and nanotubes [20-22]. Very recently, nitrogen-doped carbon nanotubes@ $\mathrm{MoS}_{2}$ nanosheets composite was reported, and it was produced by using PPy nanotubes as template for the growth 
of $\mathrm{MoS}_{2}$ nanosheets via a hydrothermal method coupled with an annealing process [18]. This material demonstrated a high capacity of $1040 \mathrm{mAh} \mathrm{g}^{-1}$ at $0.2 \mathrm{~A} \mathrm{~g}^{-1}$ and a capacity of $645.8 \mathrm{mAh}$ $\mathrm{g}^{-1}$ at $1.6 \mathrm{~A} \mathrm{~g}^{-1}$ after 200 cycles. However, the effect of the ratio between nitrogen-doped carbon nanotubes and $\mathrm{MoS}_{2}$ nanosheets on the performance was not discussed. The comparison with different nanofeatures was not mentioned either.

In this work, $\mathrm{MoS}_{2}$ nanosheets were hydrothermally grown and anchored on nanostructured nitrogen-doped carbon by using PPy nanotubes or nanoparticles as template, followed by an annealing process. The expanded interlayer distance $(0.67 \mathrm{~nm})$ of $\mathrm{MoS}_{2}$ nanosheets and the nanotube structure from PPy were both retained in the $\mathrm{MoS}_{2} / \mathrm{CNT}$ composite. Different ratios between $\mathrm{MoS}_{2}$ and $\mathrm{CNT}$ were investigated to understand the relationship between the structure and electrochemical performance. The $\mathrm{MoS}_{2} / \mathrm{CNP}$ composite was investigated as a contrast further to confirm the structural effect on the electrochemical performance. The $\mathrm{MoS}_{2} / \mathrm{CNT}$ composite with $75 \%$ of $\mathrm{MoS}_{2}$ displayed an excellent performance; including high capacity, outstanding rate capability and good cycling stability.

\section{Experimental}

2.1 Fabrication of PPy nanotubes and PPy nanoparticles

PPy nanotubes were prepared with the assistance of a reactive template formed by the anions of azo dye methyl orange (MO) and $\mathrm{FeCl}_{3}$ [23]. In a typical procedure, $\mathrm{MO}(147.3 \mathrm{mg}, 0.45 \mathrm{mmol})$ was dissolved into Milli-Q water $(90 \mathrm{ml})$ to form an orange solution, followed by addition of $\mathrm{FeCl}_{3} \cdot 6 \mathrm{H}_{2} \mathrm{O}$ (1.22 $\left.\mathrm{g}, 4.5 \mathrm{mmol}\right)$. A flocculent precipitate could be observed immediately in the solution. Then pyrrole monomer $(4.5 \mathrm{mmol})$ was added into the mixture and kept stirred for 1 day at room temperature. The produced black precipitates were collected by centrifugation 
coupled with a rinse process with Milli-Q water and ethanol to remove the impurities until the dispersion was colourless and neutral, then freeze-dried overnight to obtain PPy nanotubes.

PPy nanoparticles were obtained by employing $\mathrm{PVA} / \mathrm{FeCl}_{3}$ complexes as templates and oxidant $[24,25]$. A solution of PVA (polyvinyl alcohol, MW=50000, $5 \mathrm{wt} \%$ ) was prepared by dissolving PVA into Milli-Q water at room temperature, then oxidant $\mathrm{FeCl}_{3} \cdot 6 \mathrm{H}_{2} \mathrm{O}$ was added to form a viscous solution which was orange in colour. Pyrrole monomers were then introduced into the solution $(0.1 \mathrm{~mol} / \mathrm{L})$ for polymerization and the reaction lasted $4 \mathrm{~h}$ in an ice bath. The molar ratio of oxidant to monomer was 2.5:1. The same procedures that were used for PPy nanotubes collection were followed in order to collect PPy nanoparticles except that hot water was used in the rinsing process.

\section{2 . Fabrication of nano-featured $\mathrm{MoS}_{2} / \mathrm{PPy}$ and $\mathrm{MoS}_{2} / \mathrm{C}$ composites}

The freeze-dried PPy nanotubes or PPy nanoparticles (20 mg) were re-dispersed into Milli-Q water $(40 \mathrm{ml})$. After a sonication process of $2 \mathrm{~h}, \mathrm{Na}_{2} \mathrm{MoO}_{4}$ with a designated amount was added into the dispersion and stirred for $30 \mathrm{~min}$. As a sulfur source and reducing agent [26], L-cysteine $\left(\mathrm{C}_{3} \mathrm{H}_{7} \mathrm{NO}_{2} \mathrm{~S}\right)$ was then added (L-cysteine: $\mathrm{Na}_{2} \mathrm{MoO}_{4}=2$ : 1 , by weight $)$ and stirred for another 10 minutes. The above mixture was transferred into a $50 \mathrm{~mL}$ Teflon-lined stainless steel autoclave and subjected to a hydrothermal process at $180{ }^{\circ} \mathrm{C}$ for $24 \mathrm{~h}$ to grow $\mathrm{MoS}_{2}$ nanosheets on the surface of PPy, forming $\mathrm{MoS}_{2} / \mathrm{PPy}$ composites. The products were obtained following the procedures of centrifugation, washing 3 times with water, and a final freeze-drying process. This composite was named as $\mathrm{xMoS}_{2} / \mathrm{PPy}$, where $\mathrm{x}$ is the weight ratio between $\mathrm{MoS}_{2}$ and PPy. Neat $\mathrm{MoS}_{2}$ nanosheets were also prepared under the same conditions as control. 
The products of PPy, $\mathrm{MoS}_{2}$ nanosheets and $\mathrm{MoS}_{2} / \mathrm{PPy}$ composites were treated at $800{ }^{\circ} \mathrm{C}$ in a tube furnace under argon flow at a heating rate of $5{ }^{\circ} \mathrm{C} / \mathrm{min}$ and held at this temperature for $2 \mathrm{~h}$. The annealed PPy nanotubes/nanoparticles, $\mathrm{MoS}_{2}$ and $\mathrm{xMoS}_{2} / \mathrm{PPy}$ composites were assigned as CNT/CNP, annealed $\mathrm{MoS}_{2}$ and $\mathrm{xMoS}_{2} / \mathrm{C}$, respectively.

\subsection{Material characterizations}

The nanostructure and morphology of samples were examined using transmission electron microscopy (TEM, JEOL JEM-2200FS) and field emission scanning electron microscopy (FESEM, JEOL JSM-7500FA). Coupled energy dispersive spectroscopy (EDS) was applied to analyze the elemental distribution. BET test was conducted using Quantachrome corporation NOVA 1000 high speed gas sorption analyzer. A hemispherical energy PHOIBOS 100/150 analyzer was used to collect the X-ray photoelectron spectroscopy (XPS) data. The Raman spectra were obtained by a confocal Raman spectrometer (Jobin Yvon HR800, Horiba) using a $632.8 \mathrm{~nm}$ diode laser. FTIR spectra were collected using a FT-IR spectrometer (IRpretige-21, Shimadzu) over a range of 600 to $2000 \mathrm{~cm}^{-1}$. Thermogravimetric analysis (TGA) was conducted on a Pyris Diamond thermogravimetric/ differential thermal analyzer at a heating rate of $10{ }^{\circ} \mathrm{C}$ $\min ^{-1}$ in air flow.

\subsection{Electrochemical measurement}

The electrochemical performance of these samples as a working electrode was investigated in a 2032 coin cell coupled with a lithium foil. These cells were assembled in an argon-filled glovebox (MBrau, UNIlab Plus). The electrolyte used was $1 \mathrm{M} \mathrm{LiPF}_{6}$ in a mixture of ethylene carbonate (EC) and dimethyl carbonate (DMC) (1:1, v/v) (Aldrich). The working electrode was fabricated by coating a mixed slurry in N-Methyl-2-pyrrolidone (NMP) containing active 
materials, carbon black and polyvinylidene fluoride (PVDF) (weight ratio of 8:1:1) onto a copper foil, and then dried in a vacuum oven at $60{ }^{\circ} \mathrm{C}$ overnight. The mass loading of active materials was in a range of 1-1.2 $\mathrm{mg} \mathrm{cm}^{-2}$. Cyclic voltammograms (CV) were recorded using a Solartron SI 1287 electrochemical system at a scan rate of $0.2 \mathrm{mV} \mathrm{s}^{-1}$ over a potential range of 0.01 to $3 \mathrm{~V}$ (vs. $\mathrm{Li} / \mathrm{Li}^{+}$). Galvanostatic charge/discharge tests were conducted using a LAND CT2001A battery test system (Wuhan Jinnuo Electronics Co. Ltd.) over the potential range of 0.005 to $3 \mathrm{~V}$ (vs. $\left.\mathrm{Li} / \mathrm{Li}^{+}\right)$. Electrochemical impedance spectra (EIS) were acquired using a Gamry EIS 3000 system over a frequency range of $100 \mathrm{kHz}$ to $0.01 \mathrm{~Hz}$ with an AC perturbation of $10 \mathrm{mV}$.

\section{Results and discussion}

The schematic of the procedures to synthesize nano-featured $\mathrm{MoS}_{2} / \mathrm{C}$ composite is illustrated in Figure 1. It started with the formation of a template to nucleate and confine the growth of PPy. In the solution containing $\mathrm{MO}$, amorphous $\mathrm{FeCl}_{3}-\mathrm{MO}$ aggregates with a fibrillar structure were formed as seed template for growing PPy. As the polymerization proceeded, the templates were automatically degraded due to the reduction of iron cations, thus forming PPy with a tubular nanostructure [23]. For producing PPy nanoparticles, globule $\mathrm{PVA} / \mathrm{Fe}^{3+}$ complexes were employed as oxidant and the self-assembled templates. Due to the inherently hydrophobic property of pyrrole and the steric stabilization provided by PVA, the formed pyrrole chains tended to yield spherical polymer nanoparticles [24]. These formed PPy with distinct nanostructures were used for anchoring $\mathrm{MoS}_{2}$ nanosheets that were produced from the reaction of $\mathrm{Na}_{2} \mathrm{MoO}_{4}$ with L-cysteine. The $\mathrm{MoS}_{2} / \mathrm{C}$ composites were obtained by carbonizing PPy through an annealing process in argon. The crystallinity degree of $\mathrm{MoS}_{2}$ was improved as well during this annealing process $[6,27]$. 


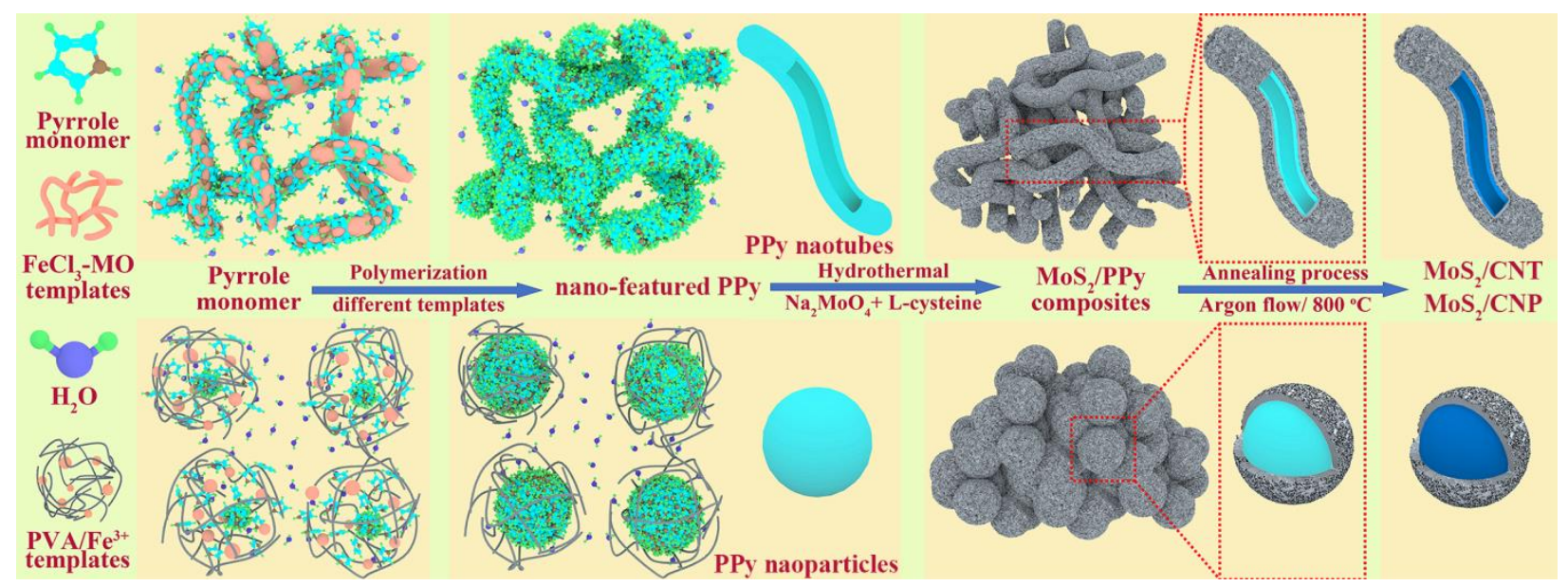

Figure 1. Schematic illustration of the procedures to synthesize $\mathrm{MoS}_{2} / \mathrm{C}$ composites.

Both PPy nanotubes and CNT exhibited a tubular architecture with a diameter in the range of 100 to $200 \mathrm{~nm}$ (SEM images, Figure $2 \mathrm{a}$ and c) with clear edges (TEM images, Figure $2 \mathrm{~b}$ and d). Neat $\mathrm{MoS}_{2}$ demonstrated a flower-like layer structure on the clusters (Figure S1a, Supporting Information), and no obvious structure changes were shown after the annealing (Figure S1b, Supporting Information). The annealed $\mathrm{MoS}_{2}$ demonstrated an expanded interlayer distance of $0.67 \mathrm{~nm}$, higher than that $0.62 \mathrm{~nm}$ for bulk $\mathrm{MoS}_{2}$ (Figure S1c, Supporting Information). After being subjected to a hydrothermal process, uniform flower-like patterns constructed with $\mathrm{MoS}_{2}$ nanosheets covered the surface of PPy nanotubes (Figure 2e). Those independent tubular nanostructures were retained in the $\mathrm{MoS}_{2} / \mathrm{PPy}$ nanotubes composite (Figure 2f, taking $2 \mathrm{MoS}_{2} / \mathrm{PPy}$ nanotubes as an example). After the annealing process, such morphology and structure were retained (Figure $2 \mathrm{~g}-\mathrm{h}$ ), and the annealed $\mathrm{MoS}_{2}$ nanosheets displayed the same expanded interlayer distance of $0.67 \mathrm{~nm}$ (Figure 2i). The SEM images of $1 \mathrm{MoS}_{2} / \mathrm{PPy}$ nanotubes, $4 \mathrm{MoS}_{2} / \mathrm{PPy}$ nanotubes and their annealed products were also collected (Figure S1 d-g, Supporting Information). $1 \mathrm{MoS}_{2} / \mathrm{PPy}$ nanotubes composite showed a similar structure as $2 \mathrm{MoS}_{2} / \mathrm{PPy}$ nanotubes: flower-like $\mathrm{MoS}_{2}$ nanosheets uniformly covered the PPy nanotubes; no 
structural changes could be found after the annealing. For $4 \mathrm{MoS}_{2} / \mathrm{PPy}$ nanotubes and $4 \mathrm{MoS}_{2} / \mathrm{CNT}$, it is noticed that $\mathrm{MoS}_{2}$ nanosheets not only just covered the surface of PPy nanotubes or CNT but also formed $\mathrm{MoS}_{2}$ clusters between the tubular nanostructures due to excess amounts of $\mathrm{MoS}_{2}$ produced. Elements $\mathrm{C}, \mathrm{N}, \mathrm{Mo}$ and $\mathrm{S}$ were detected in $2 \mathrm{MoS}_{2} / \mathrm{CNT}$ with uniform distribution (Figure $2 \mathrm{j}$ ), which evidences the formation of a hybrid structure [28]. In addition, the element oxygen was also detected, and its presence may come from organic contamination and oxidized Mo atoms $[29,30] .2 \mathrm{MoS}_{2} / \mathrm{CNT}$ may possess the best performance since it contained higher $\mathrm{MoS}_{2}$ mass loading than $1 \mathrm{MoS}_{2} / \mathrm{CNT}$, but no $\mathrm{MoS}_{2}$ clusters formed between the tubular nanostructures compared with $4 \mathrm{MoS}_{2} / \mathrm{CNT}$.

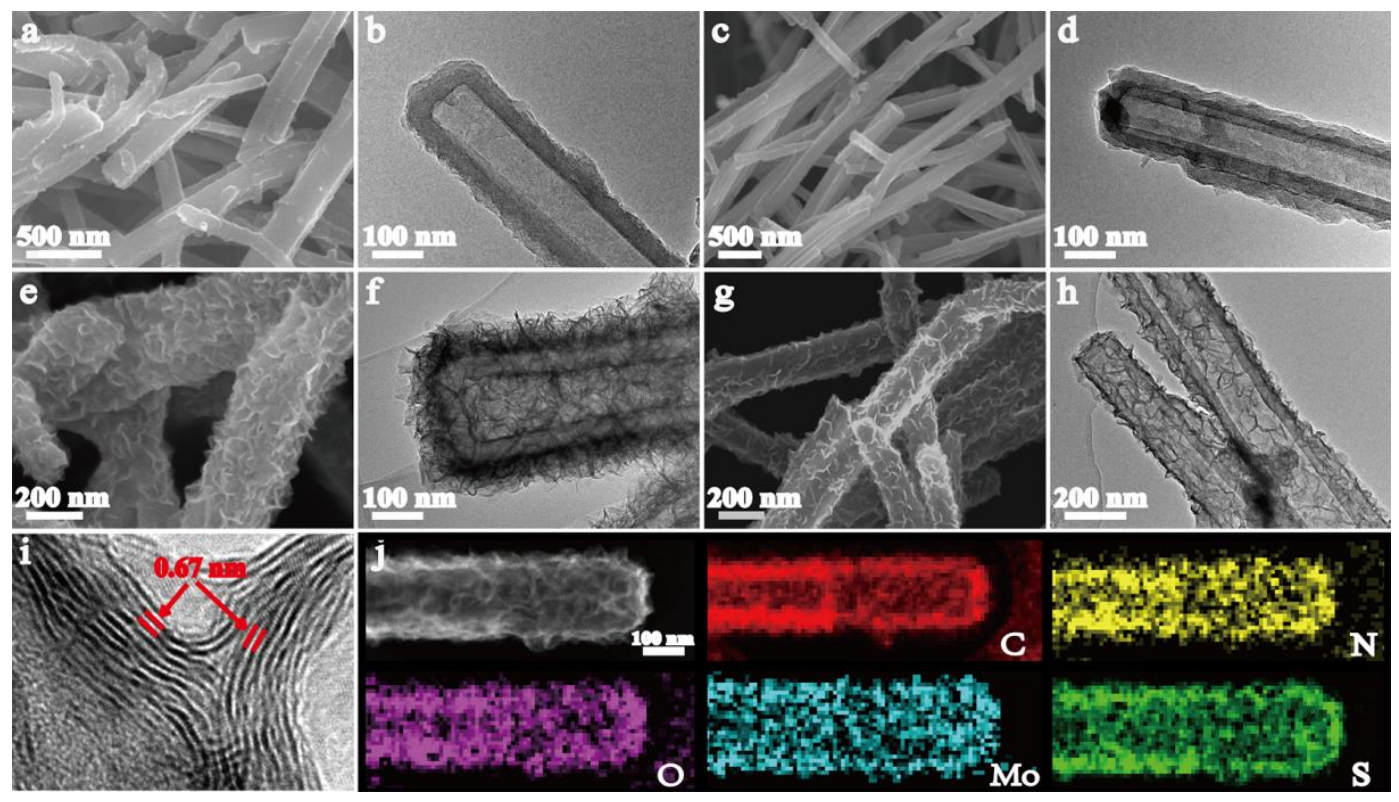

Figure 2. SEM images of PPy nanotubes (a), CNT (c), $2 \mathrm{MoS}_{2} / \mathrm{PPy}$ nanotubes (e) and $2 \mathrm{MoS}_{2} / \mathrm{CNT}$ (g); TEM images of PPy nanotubes (b), CNT (d), $2 \mathrm{MoS}_{2} / \mathrm{PPy}$ nanotubes (f) and $2 \mathrm{MoS}_{2} / \mathrm{CNT}$ (h); (i) HRTEM image of $2 \mathrm{MoS}_{2} / \mathrm{CNT}$; and (j) EDS mapping images of $2 \mathrm{MoS}_{2} / \mathrm{CNT}$. 
In order to investigate the influence of nanostructures on the electrochemical performance, the $2 \mathrm{MoS}_{2} / \mathrm{C}$ composite in the form of nanoparticles was synthesized as control. The PPy nanoparticles and CNP both displayed the same spherical nanostructures with a uniform particle size of $\sim 150 \mathrm{~nm}$ (Figure $3 \mathrm{a}$-b). During the hydrothermal reaction, few-layers $\mathrm{MoS}_{2}$ with uniform flower-like patterns were grown and completely covered the surface of PPy nanoparticles (Figure 3 c-d). After carbonization, no morphological difference was observed (Figure 3 e-f). The $\mathrm{MoS}_{2}$ with expanded interlayer $(0.67 \mathrm{~nm})$ was also observed in $2 \mathrm{MoS}_{2} / \mathrm{CNP}$, as certified by its HRTEM image (Figure 3g). The uniform distribution of $\mathrm{C}, \mathrm{N}$, Mo and S elements in EDS mapping images verifies the formation of a hybrid structure with $\mathrm{MoS}_{2}$ homogeneously distributed on the surface of CNP (Figure 3h) [28]. The element oxygen, possibly from organic contamination and oxidized Mo atoms, was also detected [29]. BET results showed that $2 \mathrm{MoS}_{2} / \mathrm{CNT}$ had a specific surface area of $39.7 \mathrm{~m}^{2} \mathrm{~g}^{-1}$ higher than that $12.2 \mathrm{~m}^{2} \mathrm{~g}^{-1}$ for $2 \mathrm{MoS}_{2} / \mathrm{CNP}$, which can also be used to elucidate the delivered good electrochemical performance by $2 \mathrm{MoS}_{2} / \mathrm{CNT}$. 

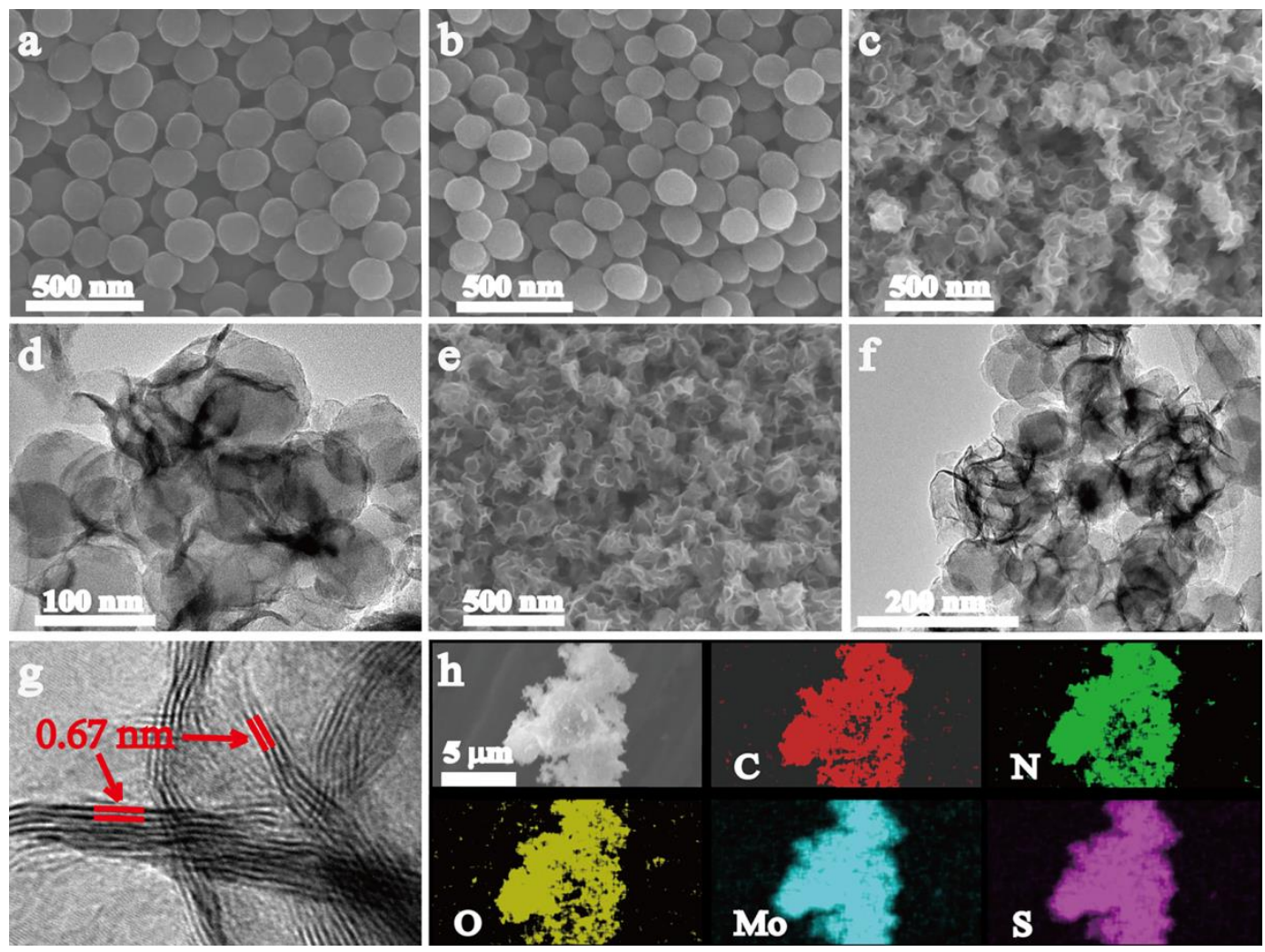

Figure 3. SEM images of PPy nanoparticles (a), CNP (b), $2 \mathrm{MoS}_{2} / \mathrm{PPy}$ nanoparticles (c) and $2 \mathrm{MoS}_{2} / \mathrm{CNP}$ (e); TEM images of $2 \mathrm{MoS}_{2} / \mathrm{PPy}$ nanoparticles (d) and $2 \mathrm{MoS}_{2} / \mathrm{CNP}$ (f); HRTEM image of $2 \mathrm{MoS}_{2} / \mathrm{CNP}(\mathrm{g})$; and (h) EDS mapping images of $2 \mathrm{MoS}_{2} / \mathrm{CNP}$.

The XPS spectra of PPy, $\mathrm{MoS}_{2}, 2 \mathrm{MoS}_{2} / \mathrm{PPy}$ composite and their annealed products were deconvoluted to analyze their chemical structure changes before and after the annealing process. The N1s and C1s XPS spectra of tubular composites are shown in Figure 4, while those for the particulate composites are displayed in Figure S2 (Supporting Information) together with the Mo3d and S2p XPS spectra of all samples. The peaks centred at 399.7 and $401 \mathrm{eV}$ in the N1s spectra (Figure 4a, Figure S2a) are attributed to the $\mathrm{N}-\mathrm{H}$ bond and $-\mathrm{N}^{+}$bond, respectively [31, 32]. However, the intensity of the $\mathrm{N}-\mathrm{H}$ peak had obviously decreased after experiencing the 
carbonization process, due to removal of most of the hydrogen atoms. In the C1s spectra (Figure 4b, Figure S2b), three peaks around 284.5, 285.6 and $287.8 \mathrm{eV}$ could be recognised as $\mathrm{sp}^{2}$ carbon (C-C), carbon in $\mathrm{C}-\mathrm{N}$ bond and $\mathrm{C}=\mathrm{O}$ bond, respectively $[30,33]$. The decreased intensity of $\mathrm{C}=\mathrm{O}$ peak after annealing is attributed to the removal of oxygen atoms, indicating a carbonization process [30]. As for the Mo3d spectrum, four typical peaks referring to $\mathrm{Mo}^{6+}$, Mo $3 \mathrm{~d} 3 / 2$, Mo 3d5/2 and S2s peaks could be found (Figure S2c) $[8,34]$. The $\mathrm{Mo}^{6+}$ peak comes from a small portion of oxidized Mo atoms, while the Mo 3d3/2 and Mo 3d5/2 peaks match well with $\mathrm{Mo}^{4+}$ in $\mathrm{MoS}_{2}$ [35]. The S2p spectrum showed two peaks around $163.4 \mathrm{eV}$ and $162.1 \mathrm{eV}$ (Figure S2d), which are ascribed to S2p1/2 and S2p3/2, respectively [18]. The XPS spectra of Mo3d and S2p showed no obvious differences before and after the annealing process, evidencing the chemical stability of $\mathrm{MoS}_{2}$.
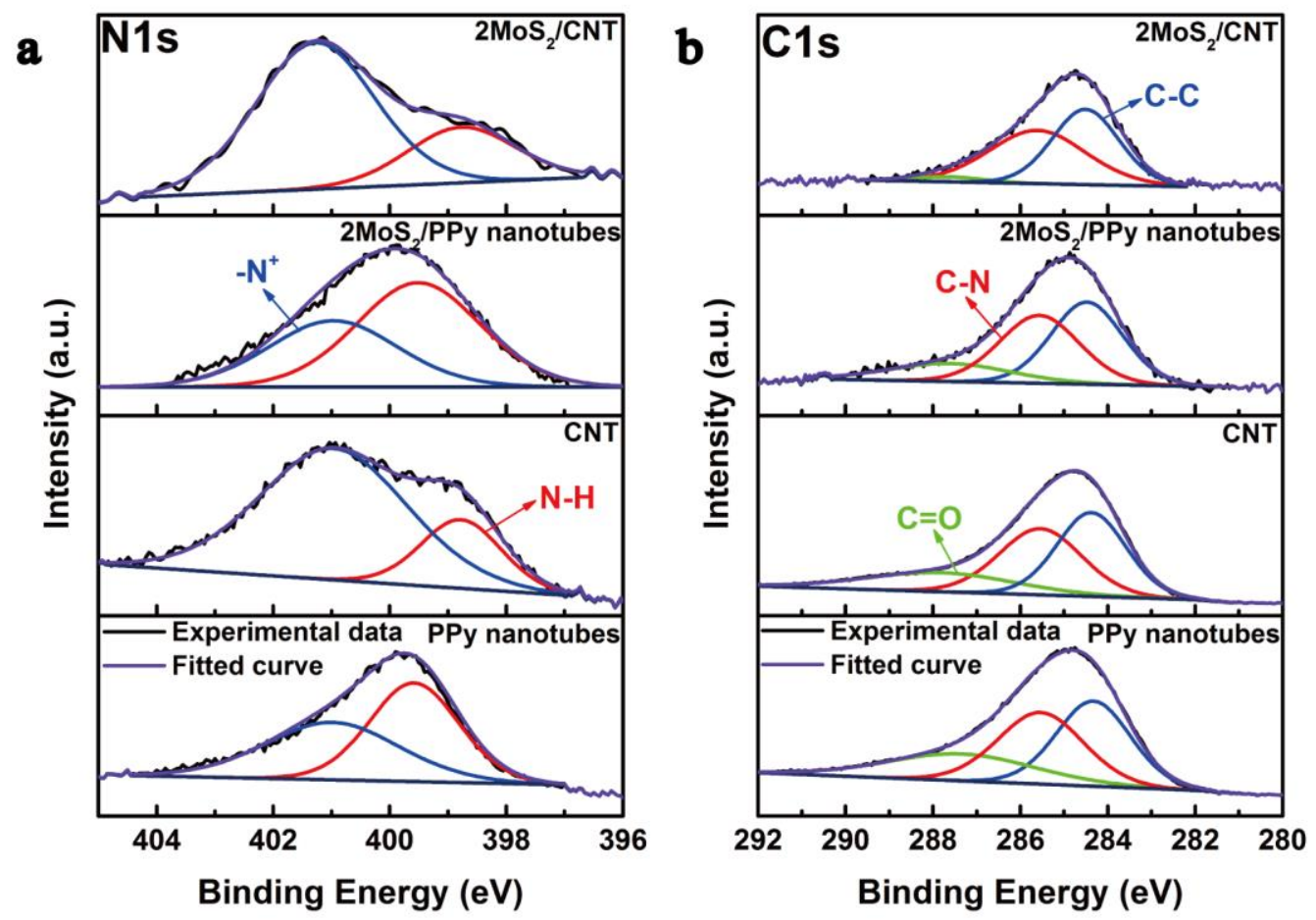

Figure 4. XPS N1s (a) and C1s (b) spectra of PPy nanotubes, CNT, 2MoS $2 / P P y$ nanotubes and $2 \mathrm{MoS}_{2} / \mathrm{CNT}$. 
Raman spectra were recorded to characterize the structure of samples. Two prominent peaks were situated at $\sim 380$ and $406 \mathrm{~cm}^{-1}$ in that for $\mathrm{MoS}_{2}$, annealed $\mathrm{MoS}_{2}, 2 \mathrm{MoS}_{2} / \mathrm{PPy}$ and $2 \mathrm{MoS}_{2} / \mathrm{C}$ composites (Figure 5a; Figure S3b, Supporting Information). They are derived from $\mathrm{MoS}_{2}$, and can be ascribed to the $\mathrm{E}_{2 \mathrm{~g}}^{1}$ mode related with the opposite vibrations of two $\mathrm{S}$ atoms versus Mo atom, and $\mathrm{A}_{1 \mathrm{~g}}$ mode corresponding to the out-of-plane symmetric displacements of $\mathrm{S}$ atoms along the c-axis, respectively $[36,37]$. The interval between those two peaks increased after the annealing, indicative of the increased layers of $\mathrm{MoS}_{2}$ nanosheets [38]. PPy, CNT, CNP, $2 \mathrm{MoS}_{2} / \mathrm{PPy}$ and $2 \mathrm{MoS}_{2} / \mathrm{C}$ composites all displayed two characteristic peaks of carbon at 1342.2 and $1593.1 \mathrm{~cm}^{-1}$ (Figure S3 a and $\mathrm{c}$, Supporting Information), corresponding to the defective/disordered structure (D band) and first order scattering of E2g mode (G band) $[8,10]$.

The chemical structure was further investigated with FTIR. A series of characteristic peaks of PPy can be identified for the samples PPy nanotubes and PPy nanoparticles (Figure 5b; Figure S3d, Supporting Information). Specifically, the peak at $1545 \mathrm{~cm}^{-1}$ stands for pyrrole ring vibration, whereas peaks at 1297 and $1031 \mathrm{~cm}^{-1}$ represent the $=\mathrm{C}-\mathrm{H}$ in-plane vibrations, and the peak at $1165 \mathrm{~cm}^{-1}$ can be assigned as the C-N stretching vibrations [39-41]. The intensity of these peaks became much weaker or even hardly identified for $2 \mathrm{MoS}_{2} / \mathrm{PPy}$ composites, which may be due to the coverage with $\mathrm{MoS}_{2}$ nanosheets [39]. All the above peaks vanished in the FTIR spectra of CNT, CNP and $2 \mathrm{MoS}_{2} / \mathrm{C}$ composites, indicating the successful transformation from PPy to nitrogen-doped carbon after the annealing.

TGA was used to analyze the thermal stability and degradation of these samples (Figure 5c; Figure S3e, Supporting Information). For CNP and CNT, the weight loss over the temperature 
range of 300 to $500^{\circ} \mathrm{C}$ represents the decomposition of nitrogen-doped carbon forming carbon dioxide. The major decomposition for annealed $\mathrm{MoS}_{2}$ started from $360^{\circ} \mathrm{C}$ which was caused by the oxidation of $\mathrm{MoS}_{2}$ to $\mathrm{MoO}_{3}[8,42]$. After heating to $700^{\circ} \mathrm{C}$ in air flow, the weight loss of $\mathrm{CNP}, \mathrm{CNT}$, annealed $\mathrm{MoS}_{2}, 2 \mathrm{MoS}_{2} / \mathrm{CNP}, 1 \mathrm{MoS}_{2} / \mathrm{CNT}, 2 \mathrm{MoS}_{2} / \mathrm{CNT}$ and $4 \mathrm{MoS}_{2} / \mathrm{CNT}$ composites was $98.5 \%, 98.2 \%, 17.6 \%, 37.5 \%, 42.4 \%, 37.2 \%$ and $33.5 \%$, respectively. The residue of CNT and CNP after TGA test was both less than 2\%, which may be ascribed to the impurities. Thus, the loading amounts of $\mathrm{MoS}_{2}$ were estimated to be $69 \%, 76 \%$ and $80 \%$ for $1 \mathrm{MoS}_{2} / \mathrm{CNT}, 2 \mathrm{MoS}_{2} / \mathrm{CNT}$ and $4 \mathrm{MoS}_{2} / \mathrm{CNT}$ composites. As expected it was $75 \%$ for $2 \mathrm{MoS}_{2} / \mathrm{CNP}$, very close to the ratio of $2 \mathrm{MoS}_{2} / \mathrm{CNT}$. The mass loading of $\mathrm{MoS}_{2}$ in the composites is different from the designated ones owing to the removal of hydrogen and oxygen atoms during the annealing process. It is also noticed that the content of $\mathrm{MoS}_{2}$ in $2 \mathrm{MoS}_{2} / \mathrm{CNT}$ and $4 \mathrm{MoS}_{2} / \mathrm{CNT}$ are very close despite a double amount of precursor $\mathrm{Na}_{2} \mathrm{MoO}_{4}$ having been used in $4 \mathrm{MoS}_{2} / \mathrm{CNT}$; which may be due to the loss of loosely bound $\mathrm{MoS}_{2}$ clusters during the repeated rinsing process.

The crystal structure of $\mathrm{PPy}, \mathrm{MoS}_{2}, 2 \mathrm{MoS}_{2} / \mathrm{PPy}$ composites and their annealed products were investigated by X-ray diffraction (Figure 5d; Figure S3f, Supporting Information). The samples CNT and CNP displayed a broad diffraction peak around $25.5^{\circ}$, revealing a d-spacing of $0.35 \mathrm{~nm}$ close to the typical d-spacing of $0.34 \mathrm{~nm}$ for graphite [40]. These broad diffraction peaks also demonstrate that amorphous carbon dominated in the CNT and CNP samples [40]. The XRD peaks of $\mathrm{MoS}_{2}$ were rather broad before the calcining process due to the low crystalline degree formed via the chemical method [43]. Those peaks became much sharper after the annealing, which can be ascribed to the increased degree of crystallinity [44]. The annealed $\mathrm{MoS}_{2}$ and $2 \mathrm{MoS}_{2} / \mathrm{C}$ composites displayed two peaks at $13.8^{\circ}$ and $33.3^{\circ}$, coincident with the typical peaks 
for hexagonal-phase $\mathrm{MoS}_{2}$ (JCPDS 37-1492). However, the peak of carbon at around $25^{\circ}$ cannot be identified in the XRD patterns of $2 \mathrm{MoS}_{2} / \mathrm{PPy}$ or $2 \mathrm{MoS}_{2} / \mathrm{C}$ composites, which may be explained by the observation that PPy or CNT/CNP were completely covered by $\mathrm{MoS}_{2}$ nanosheets [28].

a

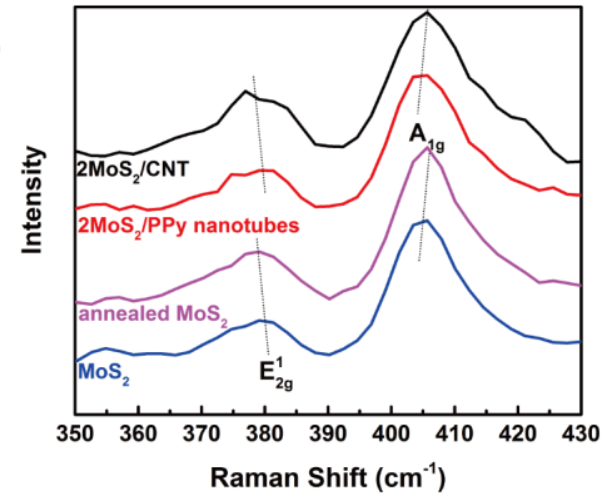

C

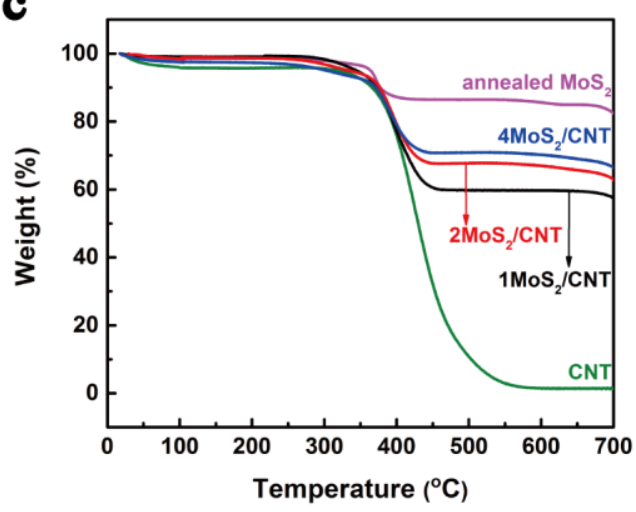

b

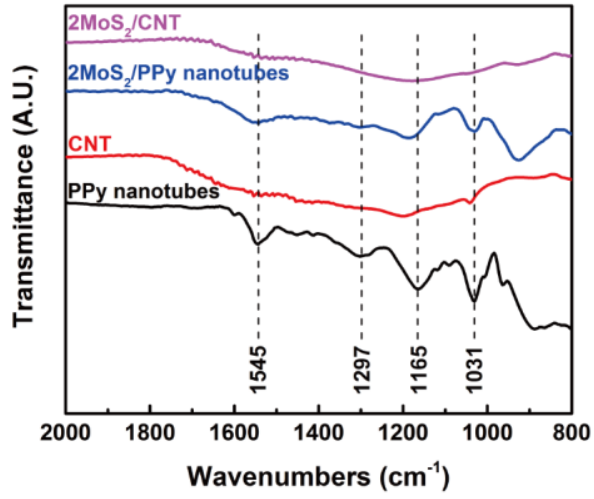

d

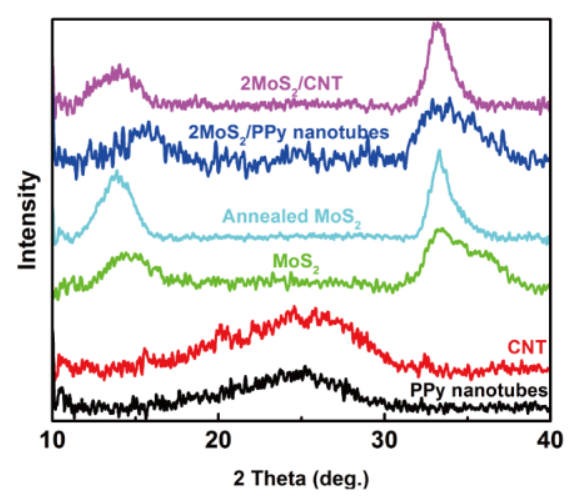

Figure 5. (a) Raman spectra of $\mathrm{MoS}_{2}$, annealed $\mathrm{MoS}_{2}, 2 \mathrm{MoS}_{2} / \mathrm{PPy}$ nanotubes and $2 \mathrm{MoS}_{2} / \mathrm{CNT}$ composites; (b) FTIR spectra of PPy nanotubes, CNT, $2 \mathrm{MoS}_{2} / \mathrm{PPy}$ nanotubes and $2 \mathrm{MoS}_{2} / \mathrm{CNT}$ composites; (c) TGA curves of CNT, annealed $\mathrm{MoS}_{2}$ and $\mathrm{MoS}_{2} / \mathrm{CNT}$ composites; (d) XRD spectra of PPy nanotubes, CNT, $\mathrm{MoS}_{2}$, annealed $\mathrm{MoS}_{2}, 2 \mathrm{MoS}_{2} / \mathrm{PPy}$ nanotubes and $2 \mathrm{MoS}_{2} / \mathrm{CNT}$ composite. 
The first three cyclic voltammograms (CV) of $\mathrm{MoS}_{2} / \mathrm{C}$ composite were recorded at a scan rate of $0.2 \mathrm{mV} \mathrm{s}^{-1}$ (Figure 6a; Figure S4 c-d, Supporting Information). Two obvious peaks can be recognized in the first cathodic scan. The formation process of octahedral $\mathrm{LixMoS}_{2}$ contributes to the first peak $\sim 0.95 \mathrm{~V}$, deriving from the insertion of lithium ions into triangular prism $\mathrm{MoS}_{2}$ $[8,45]$. The large peak at $0.5 \mathrm{~V}$ can be attributed to the reduction of $\mathrm{LixMoS}_{2}$ to $\mathrm{Mo}$ and $\mathrm{Li}_{2} \mathrm{~S}$, and formation of a solid electrolyte interface (SEI) layer [10, 45, 46]. These two peaks vanished in the following two scans indicating that the formation of SEI layer and depletion of $\mathrm{MoS}_{2}$ in our sample is irreversible $[9,27]$. Namely, $\mathrm{MoS}_{2}$ was transferred into a mixture of $\mathrm{S}$ and Mo after the first cycle. In the following two cycles, two new reduction peaks arose at $1.9 \mathrm{~V}$ and 1.1 $\mathrm{V}$ corresponding to the association of Li with $\mathrm{S}$ and Mo, respectively [45]. In the anodic cycles, a weak and broad peak around $1.6 \mathrm{~V}$ and a sharp peak at $2.35 \mathrm{~V}$ were detected, which can be ascribed to partial oxidation of Mo atoms and the delithiation process of $\mathrm{Li}_{2} \mathrm{~S}$, respectively [10]. CV curves after the first scan were much stable with the same peaks, agreeing well with the following discharge-charge curves [2]. The first three consecutive CV scans were analyzed to reveal the contributed capacities from insertion and surface capacitive. Both $2 \mathrm{MoS}_{2} / \mathrm{CNT}$ and $2 \mathrm{MoS}_{2} / \mathrm{CNP}$ displayed a very high pseudocapacitive contribution from the surface capacitive effect (Figure S5), 78\% and 70\% in the first scan; 70\% and 62\% in the following two scans along with the vanishing of irreversible capacity $(35 \%, 32 \%)$ related to the formation of SEI and the irreversible depletion of $\mathrm{MoS}_{2}[9,27]$. Higher surface capacitive contribution for $2 \mathrm{MoS}_{2} / \mathrm{CNT}$ compared to $2 \mathrm{MoS}_{2} / \mathrm{CNP}$ may be attributed to its higher surface area, which also indicates a better rate capability owing to the fast lithium storage behavior at high rate [10].

The first three discharge-charge curves of $2 \mathrm{MoS}_{2} / \mathrm{CNT}$ composite were collected at a current density of $100 \mathrm{~mA} \mathrm{~g}^{-1}$ over the potential range of 0.005 to $3 \mathrm{~V}$ (Figure $6 \mathrm{~b}$ ). The plateaus are in 
good accordance with the peaks in the CV curves. The $2 \mathrm{MoS}_{2} / \mathrm{CNT}$ composite delivered a high initial discharge capacity of $1627 \mathrm{mAh} \mathrm{g}^{-1}$ and a reversible capacity of $1233 \mathrm{mAh} \mathrm{g}^{-1}$ with a Coulombic efficiency of $76 \%$. The loss of initial capacity can be attributed to formation of SEI and the trapping of lithium ions in some defect sites or disordered structures [8, 47]. This coulombic efficiency was higher than the reported rose-like $\mathrm{MoS}_{2} /$ nitrogen-containing carbon/graphene hybrids (72.8\%) [6], nitrogen-doped carbon@ $\mathrm{MoS}_{2}$ nanoboxes (59.2\%) [19], and $\mathrm{MoS}_{2} / \mathrm{N}$-doped carbon on carbon microtubes (69\%) [48], indicating an easy access of electrolyte to the $2 \mathrm{MoS}_{2} / \mathrm{CNT}$ with a $3 \mathrm{D}$ tubular nanostructure.

The influence of nanostructures on the electrochemical performance was investigated by using $2 \mathrm{MoS}_{2} / \mathrm{CNP}$ as control. As expected, this control sample displayed very similar CV and discharge-charge curves (Figure S4 a-b, Supporting Information). However, it displayed an initial capacity of $1104 \mathrm{mAh} \mathrm{g}^{-1}$ and a reversible capacity of $850 \mathrm{mAh} \mathrm{g}^{-1}$ (77\%), much lower than that of $2 \mathrm{MoS}_{2} / \mathrm{CNT}$. As they had same components and contents (TGA results), the increased capacity for $2 \mathrm{MoS}_{2} / \mathrm{CNT}$ can be attributed to the $3 \mathrm{D}$ tubular nanostructures that can provide large surface area for lithium storage. The merits of the 3D tubular nanostructure in $2 \mathrm{MoS}_{2} / \mathrm{CNT}$ were also reflected in the following rate capability and cycling stability.

The rate capability of $\mathrm{MoS}_{2} /$ nitrogen-doped carbon composites was investigated at five different current densities ranging from 0.1 to $2 \mathrm{~A} \mathrm{~g}^{-1}$. It was found that $2 \mathrm{MoS}_{2} / \mathrm{CNT}$ possessed much higher capacity than $1 \mathrm{MoS}_{2} / \mathrm{CNT}, 4 \mathrm{MoS}_{2} / \mathrm{CNT}$ and $2 \mathrm{MoS}_{2} / \mathrm{CNP}$ (Figure $6 \mathrm{c}$ ) as well as CNT and annealed $\mathrm{MoS}_{2}$ (Figure S4e, Supporting Information). The capacity delivered from $2 \mathrm{MoS}_{2} / \mathrm{CNT}$ was $1232,1162,1091,1030,947 \mathrm{mAh} \mathrm{g}^{-1}$ at a current density of $0.1,0.2,0.5,1$ and $2 \mathrm{~A} \mathrm{~g}^{-1}$, respectively. For $2 \mathrm{MoS}_{2} / \mathrm{CNP}$, it was only 827, 785, 655, 459, $213 \mathrm{mAh} \mathrm{g}^{-1}$. After the current density was reversed to $0.1 \mathrm{~A} \mathrm{~g} \mathrm{~g}^{-1}$, the capacity of $2 \mathrm{MoS}_{2} / \mathrm{CNT}$ was not just fully recovered but 
increased to $1307 \mathrm{mAh} \mathrm{g}^{-1}$, while a decreased capacity of $738 \mathrm{mAh} \mathrm{g}^{-1}$ was shown for $2 \mathrm{MoS}_{2} / \mathrm{CNP}$. Undoubtedly, this better electrochemical performance of $2 \mathrm{MoS}_{2} / \mathrm{CNT}$ comes from its $3 \mathrm{D}$ tubular nanostructures. It is also noticed that $1 \mathrm{MoS}_{2} / \mathrm{CNT}$ showed a lower capacity, which may be ascribed to its lower content of $\mathrm{MoS}_{2}$. The $4 \mathrm{MoS}_{2} / \mathrm{CNT}$ with the highest content of $\mathrm{MoS}_{2}$ displayed a similar capacity at low current density as $1 \mathrm{MoS}_{2} / \mathrm{CNT}$, but much lower capacity at high current density. This poor rate performance may be attributed to the formation of $\mathrm{MoS}_{2}$ clusters between the tubular structures, which may affect the diffusion pathways for ions. The electrochemical performance of $2 \mathrm{MoS}_{2} / \mathrm{CNT}$ is better than or comparable to most of the reported hybrid $\mathrm{MoS}_{2} / \mathrm{C}$ materials (Table S1, Supporting Information), such as the $850 \mathrm{mAh} \mathrm{g}^{-1}$ at $1 \mathrm{~A} \mathrm{~g}^{-1}$ from the ultrathin $\mathrm{MoS}_{2} /$ nitrogen-doped graphene nanosheets [49], $926 \mathrm{mAh} \mathrm{g}^{-1}$ at $2 \mathrm{~A} \mathrm{~g}^{-1}$ from $\mathrm{MoS}_{2} /$ nitrogen-doped carbon hybrid nanorods [7], and $645 \mathrm{mAh} \mathrm{g}^{-1}$ at $1.5 \mathrm{~A} \mathrm{~g}^{-1}$ from nitrogendoped carbon embedded $\mathrm{MoS}_{2}$ microspheres [50]. It is also better than the 3D N-doped carbon nanotube@ $\mathrm{MoS}_{2}$ nanosheets with approximate contents and similar fabrication method [18], which delivered a capacity of $1040 \mathrm{mAh} \mathrm{g}^{-1}$ at $0.2 \mathrm{~A} \mathrm{~g}^{-1}$ and $651 \mathrm{mAh} \mathrm{g}^{-1}$ at $1.6 \mathrm{~A} \mathrm{~g}^{-1}$.

The cycling stability of $2 \mathrm{MoS}_{2} / \mathrm{CNT}$ and $2 \mathrm{MoS}_{2} / \mathrm{CNP}$ samples was evaluated at a current density of $1 \mathrm{~A} \mathrm{~g}^{-1}$ (Figure $6 \mathrm{~d}$ ). The $2 \mathrm{MoS}_{2} / \mathrm{CNT}$ showed a higher capacity over the prolonged cycling process than $2 \mathrm{MoS}_{2} / \mathrm{CNP}$ as well as annealed $\mathrm{MoS}_{2}$ and CNT samples (Figure S4f, Supporting Information). A discharge capacity of $754 \mathrm{mAh} \mathrm{g}^{-1}$ was delivered by $2 \mathrm{MoS}_{2} / \mathrm{CNT}$ composite at the $1000^{\text {th }}$ cycle, much higher than the capacity of $113 \mathrm{mAh} \mathrm{g}^{-1}, 298 \mathrm{mAh} \mathrm{g}^{-1}$ and $257 \mathrm{mAh} \mathrm{g}^{-1}$ for $2 \mathrm{MoS}_{2} / \mathrm{CNP}$, annealed $\mathrm{MoS}_{2}$ and CNT, respectively. The capacity fading from the 1 st cycle to 80th cycle can be explained by the formation of SEI layer and some lithium trapped in defect sites; while the second capacity dropping from the 200th cycle to 350th cycle may be caused by the loss of active material and electrolyte occurred under such a rigorous cycling test condition 
[51]. More importantly, $2 \mathrm{MoS}_{2} / \mathrm{CNT}$ displayed a coulombic efficiency of around $100 \%$ over the whole cycling process, indicting an outstanding cycling stability.
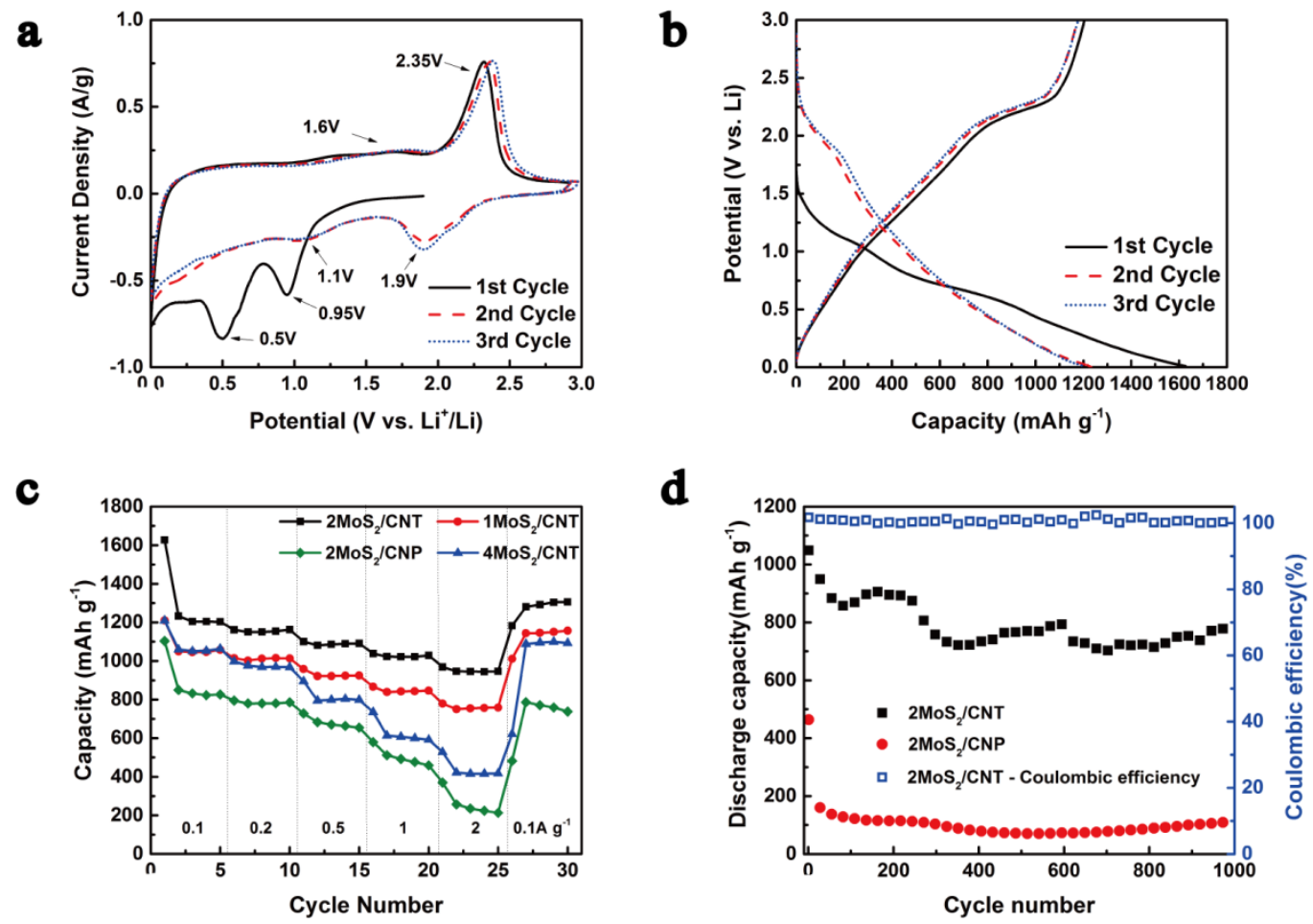

Figure 6. (a) The first three cyclic voltammograms of $2 \mathrm{MoS}_{2} / \mathrm{CNT}$ composite at a scan rate of $0.2 \mathrm{mV} \mathrm{s}^{-1}$; (b) The first three discharge/charge curves of $2 \mathrm{MoS}_{2} / \mathrm{CNT}$ composite at a current density of $100 \mathrm{~mA} \mathrm{~g}^{-1}$ over a potential range of 0.005 to $3 \mathrm{~V}$; (c) Rate capability of $2 \mathrm{MoS}_{2} / \mathrm{CNP}$ and $\mathrm{MoS}_{2} / \mathrm{CNT}$ composites; (d) Cycling stability of $2 \mathrm{MoS}_{2} / \mathrm{CNP}$ and $2 \mathrm{MoS}_{2} / \mathrm{CNT}$ composite at a current density of $1 \mathrm{~A} \mathrm{~g}^{-1}$.

To investigate the electrochemical impedance properties, Nyquist plots of $\mathrm{MoS}_{2} / \mathrm{CNT}$ composites were recorded after the cycling stability test (Figure 7), which were fitted using an equivalent circuit model (Figure 7b). The slope of the line at low frequency represents the 
diffusion rate of electrolyte ions, and the semicircle is related with the charge transfer resistance at the interface of electrolyte and active materials, while the intercept at high frequency is assigned as contact resistance [35]. Parameters Rs, Rct, CPE and Wo used in the model represent contact resistance, charge transfer resistance, constant phase element and Warburg impedance, respectively $[10,52]$. The increased slope could be attributed to the increased diffusion pathways provided by the tubular nanostructure of CNT. Nyquist plots of fresh battery cells (Figure S6) showed that $4 \mathrm{MoS}_{2} / \mathrm{CNT}$ has the largest Rct of $842 \Omega$ compared with $617 \Omega$ for $2 \mathrm{MoS}_{2} / \mathrm{CNT}$ and $608 \Omega$ for $1 \mathrm{MoS}_{2} / \mathrm{CNT}$, due to the extra MoS2 clusters formed between the tubular structure. After cycling test, the charge transfer resistance was improved due to the enhanced kinetic performance upon cycling $[10,11]$. The sample $1 \mathrm{MoS} 2 / \mathrm{CNT}$ possessed the smallest Rct value, $188 \Omega$ compared with $257 \Omega$ for $2 \mathrm{MoS}_{2} / \mathrm{CNT}$ and $624 \Omega$ for $4 \mathrm{MoS}_{2} / \mathrm{CNT}$. The decreased amplitude of Rct for these samples further verified the important function of CNT as conductive structural material. Electrochemical impedance spectroscopy of the $2 \mathrm{MoS}_{2} / \mathrm{CNT}$ composite at different cycling numbers (Figure 7b) was also conducted to further characterize this sample by analyzing the impedance changes related with the cycling test. The Rct value was $617,355,301$, 265 and $257 \Omega$ at $0,10,20,50$ and 100 cycles, respectively. The decreased charge transfer resistance well demonstrated the enhanced kinetic performance upon cycling [10, 11]. Moreover, the slopes increased with the cycling numbers, which may be attributed to the introduction of new micro-channels during cycling, thus facilitating the diffusion of electrolyte ions [8]. 

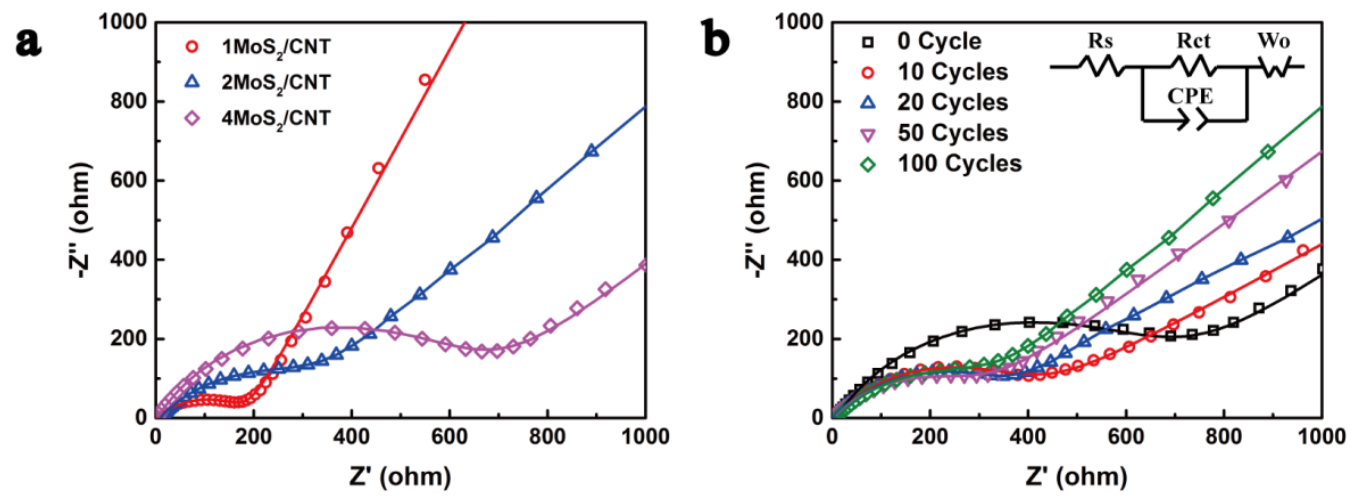

Figure 7. (a) Nyquist plots (symbols) and fitting curves (lines) of $\mathrm{MoS}_{2} / \mathrm{CNT}$ composites at the open circuit potential over a frequency range of $100 \mathrm{kHz}$ to $10 \mathrm{mHz}$; (b) Nyquist plots (symbols) and fitting curves (lines) of $2 \mathrm{MoS}_{2} / \mathrm{CNT}$ composite at different cycling numbers, inset in (b) is the equivalent circuit.

\section{Conclusion}

Tubular $\mathrm{MoS}_{2} / \mathrm{CNT}$ composites were synthesized by using a hydrothermal reaction with PPy nanotubes as templates coupled with a subsequent annealing process. The important role of tubular nanostructure in improving the electrochemical performance has been demonstrated by using $\mathrm{MoS}_{2} / \mathrm{CNP}$ with same components as control. The $\mathrm{MoS}_{2} / \mathrm{CNT}$ composite with $75 \%$ of $\mathrm{MoS}_{2}$ affords a high capacity (1232 $\mathrm{mAh} \mathrm{g}^{-1}$ at $0.1 \mathrm{~A} \mathrm{~g}^{-1}$ ), outstanding rate capability (947 mAh $\mathrm{g}^{-1}$ at $2 \mathrm{~A} \mathrm{~g}^{-1}$ ), and good cycling stability (754 $\mathrm{mAh} \mathrm{g}^{-1}$ after 1000 cycles at $\left.1 \mathrm{~A} \mathrm{~g}^{-1}\right)$. This excellent electrochemical performance may be ascribed to the large interlayer distance of $\mathrm{MoS}_{2}$, the introduced nitrogen-doped carbon component with abundant active sites and improved conductivity, as well as the created 3D tubular nanostructures facilitating ions transport. This work demonstrates a straightforward and controllable method to produce 3D nanostructures with improved electrochemical performance. 


\section{Acknowledgements}

Funding from the Australian Research Council Centre of Excellence Scheme (Project Number CE 140100012) is gratefully acknowledged. The authors would like to thank the Australian National Nanofabrication Facility-Materials node (ANFF) and the UOW Electron Microscopy Centre for equipment use. Y. C. acknowledges the support of the CSC scholarship from the Ministry of Education of P. R. China.

\section{References}

[1] X.Y. Yang, J.J. Xu, Z.W. Chang, D. Bao, Y.B. Yin, T. Liu, J.M. Yan, D.P. Liu, Y. Zhang, X.B. Zhang, Blood-capillary-inspired, free-standing, flexible, and low-cost super-hydrophobic N-CNTs@ SS cathodes for high-capacity, high-rate, and stable Li-Air batteries, Adv. Energy Mater. (2018) 1702242.

[2] J. Wang, J. Liu, D. Chao, J. Yan, J. Lin, Z.X. Shen, Self-assembly of honeycomb-like MoS2 nanoarchitectures anchored into graphene foam for enhanced lithium-ion storage, Adv. Mater. 26 (2014) 7162-7169.

[3] B. Chen, Y. Meng, F. He, E. Liu, C. Shi, C. He, L. Ma, Q. Li, J. Li, N. Zhao, Thermal decomposition-reduced layer-by-layer nitrogen-doped graphene/ $\mathrm{MoS}_{2} /$ nitrogen-doped graphene heterostructure for promising lithium-ion batteries, Nano Energy 41 (2017) 154-163.

[4] X. Zhang, X. Li, J. Liang, Y. Zhu, Y. Qian, Synthesis of $\mathrm{MoS}_{2} @ \mathrm{C}$ nanotubes via the kirkendall effect with enhanced electrochemical performance for lithium ion and sodium ion batteries, Small 12 (2016) 2484-2491. 
[5] P. Zhang, F. Qin, L. Zou, M. Wang, K. Zhang, Y. Lai, J. Li, Few-layered $\mathrm{MoS}_{2} / \mathrm{C}$ with expanding d-spacing as a high-performance anode for sodium-ion batteries, Nanoscale 9 (2017) 12189-12195.

[6] Z. Guo, Y. Zhong, Z. Xuan, C. Mao, F. Du, G. Li, Polypyrrole-assisted synthesis of roselike $\mathrm{MoS}_{2} /$ nitrogen-containing carbon/graphene hybrids and their robust lithium storage performances, RSC Adv. 5 (2015) 62624-62629.

[7] Q. Zhu, C. Zhao, Y. Bian, C. Mao, H. Peng, G. Li, K. Chen, $\mathrm{MoS}_{2} /$ nitrogen-doped carbon hybrid nanorods with expanded interlayer spacing as an advanced anode material for lithium ion batteries, Synth. Met. 235 (2018) 103-109.

[8] Y. Chao, R. Jalili, Y. Ge, C. Wang, T. Zheng, K. Shu, G.G. Wallace, Self-assembly of flexible free-Standing 3D porous $\mathrm{MoS}_{2}$-reduced graphene oxide structure for high-performance lithium-ion batteries, Adv. Funct. Mater. 27 (2017) 1700234.

[9] Z. Hu, Q. Liu, W. Sun, W. Li, Z. Tao, S.L. Chou, J. Chen, S.X. Dou, MoS 2 with an intercalation reaction as a long-life anode material for lithium ion batteries, Inorg. Chem. Front. 3 (2016) 532-535.

[10] Y. Ge, C. Wang, Y. Zhao, Y. Liu, Y. Chao, T. Zheng, G.G. Wallace, An electrosynthesized 3D porous molybdenum sulfide/graphene film with enhanced electrochemical performance for lithium storage, Small 14 (2018) 1703096.

[11] F. Zhou, S. Xin, H.W. Liang, L.T. Song, S.H. Yu, Carbon nanofibers decorated with molybdenum disulfide nanosheets: synergistic lithium storage and enhanced electrochemical performance, Angew. Chem. Int. Ed. 53 (2014) 11552-11556. 
[12] Y. Pang, S. Zhang, L. Liu, J. Liang, Z. Sun, Y. Wang, C. Xiao, D. Ding, S. Ding, Few-layer $\mathrm{MoS}_{2}$ anchored at nitrogen-doped carbon ribbons for sodium-ion battery anodes with high rate performance, J. Mater. Chem. A 5 (2017) 17963-17972.

[13] L.-F. Chen, X.-D. Zhang, H.-W. Liang, M. Kong, Q.-F. Guan, P. Chen, Z.-Y. Wu, S.-H. Yu, Synthesis of nitrogen-doped porous carbon nanofibers as an efficient electrode material for supercapacitors, ACS Nano 6 (2012) 7092-7102.

[14] J. Ruan, T. Yuan, Y. Pang, S. Luo, C. Peng, J. Yang, S. Zheng, Nitrogen and sulfur dualdoped carbon films as flexible free-standing anodes for Li-ion and Na-ion batteries, Carbon 126 (2018) 9-16.

[15] G. Xu, B. Ding, P. Nie, L. Shen, J. Wang, X. Zhang, Porous nitrogen-doped carbon nanotubes derived from tubular polypyrrole for energy-storage applications, Chem. Eur. J. 19 (2013) 12306-12312.

[16] F. Zhao, X. Zhao, B. Peng, F. Gan, M. Yao, W. Tan, J. Dong, Q. Zhang, Polyimide-derived carbon nanofiber membranes as anodes for high-performance flexible lithium ion batteries, Chin. Chem. Lett. 2017. https://doi.org/10.1016/j.cclet.2017.12.015

[17] Y. Han, Y. Ge, Y. Chao, C. Wang, G.G. Wallace, Recent progress in 2D materials for flexible supercapacitors, J. Energy Chem. 27 (2018) 57-72.

[18] X. Zhao, G. Wang, X. Liu, X. Zheng, H. Wang, Ultrathin $\mathrm{MoS}_{2}$ with expanded interlayers supported on hierarchical polypyrrole-derived amorphous N-doped carbon tubular structures for high-performance Li/Na-ion batteries, Nano Res. 11(2017) 3603-3618.

[19] X.Y. Yu, H. Hu, Y. Wang, H. Chen, X.W. Lou, Ultrathin $\mathrm{MoS}_{2}$ nanosheets supported on Ndoped carbon nanoboxes with enhanced lithium storage and electrocatalytic properties, Angew. Chem. Int. Ed. 54 (2015) 7395-7398. 
[20] H.g. Wang, Z. Wu, F.l. Meng, D.l. Ma, X.l. Huang, L.m. Wang, X.b. Zhang, Nitrogendoped porous carbon nanosheets as low-cost, high-performance Aanode material for sodium-ion batteries, ChemSusChem, 6 (2013) 56-60.

[21] D.P. Dubal, N.R. Chodankar, Z. Caban-Huertas, F. Wolfart, M. Vidotti, R. Holze, C.D. Lokhande, P. Gomez-Romero, Synthetic approach from polypyrrole nanotubes to nitrogen doped pyrolyzed carbon nanotubes for asymmetric supercapacitors, J.Power Sources 308 (2016) 158165.

[22] L. Qie, W.M. Chen, Z.H. Wang, Q.G. Shao, X. Li, L.X. Yuan, X.L. Hu, W.X. Zhang, Y.H. Huang, Nitrogen-doped porous carbon nanofiber webs as anodes for lithium ion batteries with a superhigh capacity and rate capability, Adv. Mater. 24 (2012) 2047-2050.

[23] X. Yang, Z. Zhu, T. Dai, Y. Lu, Facile fabrication of functional polypyrrole nanotubes via a reactive self-degraded template, Macromol. Rapid Comm. 26 (2005) 1736-1740.

[24] J.Y. Hong, H. Yoon, J. Jang, Kinetic study of the formation of polypyrrole nanoparticles in water-soluble polymer/metal cation systems: a light-scattering analysis, Small 6 (2010) 679-686. [25] Y. Ge, C. Wang, K. Shu, C. Zhao, X. Jia, S. Gambhir, G.G. Wallace, A facile approach for fabrication of mechanically strong graphene/polypyrrole films with large areal capacitance for supercapacitor applications, RSC Adv. 5 (2015) 102643-102651.

[26] K. Chang, W. Chen, L-cysteine-assisted synthesis of layered $\mathrm{MoS}_{2} /$ graphene composites with excellent electrochemical performances for lithium ion batteries, ACS Nano 5 (2011) 47204728.

[27] X. Wang, G. Li, M.H. Seo, F.M. Hassan, M.A. Hoque, Z. Chen, Sulfur atoms bridging fewlayered $\mathrm{MoS}_{2}$ with S-doped graphene enable highly robust anode for lithium-ion batteries, Adv. Energy Mater. 5 (2015) 1501106. 
[28] C. Chang, X. Yang, S. Xiang, H. Que, M. Li, Layered $\mathrm{MoS}_{2} / \mathrm{PPy}$ nanotube composites with enhanced performance for supercapacitors, J. Mater. Sci-Mater. El. 28 (2017) 1777-1784.

[29] H. Liu, X. Chen, L. Deng, X. Su, K. Guo, Z. Zhu, Preparation of ultrathin 2D $\mathrm{MoS}_{2}$ /graphene heterostructure assembled foam-like structure with enhanced electrochemical performance for lithium-ion batteries, Electrochim. Acta 206 (2016) 184-191.

[30] B. Schweiger, J. Kim, Y.J. Kim, M. Ulbricht, Electropolymerized molecularly imprinted polypyrrole film for sensing of clofibric acid, Sensors 15 (2015) 4870-4889.

[31] H. Tang, J. Wang, H. Yin, H. Zhao, D. Wang, Z. Tang, Growth of polypyrrole ultrathin films on $\mathrm{MoS}_{2}$ monolayers as high-performance supercapacitor electrodes, Adv. Mater. 27 (2015) 1117-1123.

[32] J. Cao, Y. Wang, J. Chen, X. Li, F.C. Walsh, J.-H. Ouyang, D. Jia, Y. Zhou, Threedimensional graphene oxide/polypyrrole composite electrodes fabricated by one-step electrodeposition for high performance supercapacitors, J. Mater. Chem. A 3 (2015) 1444514457.

[33] D. Xie, D.H. Wang, W.J. Tang, X.H. Xia, Y.J. Zhang, X.L. Wang, C.D. Gu, J.P. Tu, Binder-free network-enabled $\mathrm{MoS}_{2}$-PPY-rGO ternary electrode for high capacity and excellent stability of lithium storage, J. Power Sources 307 (2016) 510-518.

[34] S.-K. Park, S.-H. Yu, S. Woo, B. Quan, D.-C. Lee, M.K. Kim, Y.-E. Sung, Y. Piao, A simple 1-cysteine-assisted method for the growth of $\mathrm{MoS}_{2}$ nanosheets on carbon nanotubes for high-performance lithium ion batteries, Dalton Trans. 42 (2013) 2399-2405.

[35] Y. Chen, W. Ma, K. Cai, X. Yang, C. Huang, In situ growth of polypyrrole onto threedimensional tubular $\mathrm{MoS}_{2}$ as an advanced negative electrode material for supercapacitor, Electrochim. Acta 246 (2017) 615-624. 
[36] L. Chen, F. Chen, N. Tronganh, M. Lu, Y. Jiang, Y. Gao, Z. Jiao, L. Cheng, B. Zhao, $\mathrm{MoS}_{2} /$ graphene nanocomposite with enlarged interlayer distance as a high performance anode material for lithium-ion battery, J. Mater. Res. 31 (2016) 3151-3160.

[37] J. Ye, L. Ma, W. Chen, Y. Ma, F. Huang, C. Gao, J.Y. Lee, Supramolecule-mediated synthesis of $\mathrm{MoS}_{2} /$ reduced graphene oxide composites with enhanced electrochemical performance for reversible lithium storage, J. Mater. Chem. A 3 (2015) 6884-6893.

[38] H. Li, Q. Zhang, C.C.R. Yap, B.K. Tay, T.H.T. Edwin, A. Olivier, D. Baillargeat, From bulk to monolayer $\mathrm{MoS}_{2}$ : evolution of raman scattering, Adv. Funct. Mater. 22 (2012) 13851390.

[39] P. Gemeiner, J. Kuliček, M. Mikula, M. Hatala, L. Švorc, L. Hlavatá, M. Mičušík, M. Omastová, Polypyrrole-coated multi-walled carbon nanotubes for the simple preparation of counter electrodes in dye-sensitized solar cells, Synth. Met. 210 (2015) 323-331.

[40] Y. Ma, S. Jiang, G. Jian, H. Tao, L. Yu, X. Wang, X. Wang, J. Zhu, Z. Hu, Y. Chen, CNx nanofibers converted from polypyrrole nanowires as platinum support for methanol oxidation, Energy Environ. Sci. 2 (2009) 224-229.

[41] Y. Fu, Y.-S. Su, A. Manthiram, Sulfur-polypyrrole composite cathodes for lithium-sulfur batteries, J. Electrochem. Soc. 159 (2012) A1420-A1424.

[42] N. Kapil, A. Singh, M. Singh, D. Das, Efficient $\mathrm{MoS}_{2}$ exfoliation by cross-b-amyloid nanotubes for multistimuli-responsive and biodegradable aqueous dispersions, Angew. Chem. Int. Ed. 55 (2016) 7772-7776.

[43] F. Pan, J. Wang, Z. Yang, L. Gu, Y. Yu, $\mathrm{MoS}_{2}$-graphene nanosheet-CNT hybrids with excellent electrochemical performances for lithium-ion batteries, RSC Adv. 5 (2015) 7751877526. 
[44] Y.-X. Zeng, X.-W. Zhong, Z.-Q. Liu, S. Chen, N. Li, Preparation and enhancement of thermal conductivity of heat transfer oil-based $\mathrm{MoS}_{2}$ nanofluids, J. Nanomater. 2013 (2013) Article ID 270490.

[45] J. Xiao, X. Wang, X.Q. Yang, S. Xun, G. Liu, P.K. Koech, J. Liu, J.P. Lemmon, Electrochemically induced high capacity displacement reaction of $\mathrm{PEO} / \mathrm{MoS}_{2} /$ graphene nanocomposites with lithium, Adv. Funct. Mater. 21(2011) 2840-2846.

[46] Y. Zhang, Y. Wang, J. Yang, W. Shi, H. Yang, W. Huang, X. Dong, $\mathrm{MoS}_{2}$ coated hollow carbon spheres for anodes of lithium ion batteries, 2D Mater. 3 (2016) 024001.

[47] J. Wang, J. Liu, J. Luo, P. Liang, D. Chao, L. Lai, J. Lin, Z. Shen, $\mathrm{MoS}_{2}$ architectures supported on graphene foam/carbon nanotube hybrid films: highly integrated frameworks with ideal contact for superior lithium storage, J. Mater. Chem. A 3 (2015) 17534-17543.

[48] D. Xie, X. Xia, W. Tang, Y. Zhong, Y. Wang, D. Wang, X. Wang, J. Tu, Novel carbon channels from loofah sponge for construction of metal sulfide/carbon composites with robust electrochemical energy storage, J. Mater. Chem. A 5 (2017) 7 578-7585.

[49] K. Chang, D. Geng, X. Li, J. Yang, Y. Tang, M. Cai, R. Li, X. Sun, Ultrathin $\mathrm{MoS}_{2} /$ nitrogen-doped graphene nanosheets with highly reversible lithium storage, Adv. Energy Mater. 3 (2013) 839-844.

[50] D. Xie, X. Xia, Y. Wang, D. Wang, Y. Zhong, W. Tang, X. Wang, J. Tu, Nitrogen-doped carbon embedded $\mathrm{MoS}_{2}$ microspheres as advanced anodes for lithium-and sodium-ion batteries, Chem. Eur. J. 22 (2016) 11617-11623.

[51] J. Vetter, P. Novak, M.R. Wagner, C. Veit, K.-C. Moller, J.O. Besenhard, M. Winter, M. Wohlfahrt-Mehrens, C. Vogler, A. Hammouche, Ageing mechanisms in lithium-ion batteries, J. Power Sources, 147(2005) 269-281. 
[52] Y. Li, L.B. Kong, M.C. Liu, W.B. Zhang, L. Kang, One-step synthesis of micro/nano flower-like $\mathrm{Ni}_{3} \mathrm{~V}_{2} \mathrm{O}_{8}$ as anode for Li-ion batteries, Mater. Lett. 186 (2017) 289-292. 


\section{Supporting Information}

\section{Tuning the three dimensional nanostructured molybdenum}

\section{disulfide/nitrogen-doped carbon composite for high lithium storage}

\section{performance}

Yunfeng Chao ${ }^{\mathrm{a}}$, Yu Ge $\mathrm{Ge}^{\mathrm{a}}$, Yong Zhao ${ }^{\mathrm{a}}$, Jicheng Jiang ${ }^{\mathrm{b}}$, Caiyun Wang ${ }^{\mathrm{a}, *}$, Chunyan Qin $^{\mathrm{a}}$, Amruthalakshmi Vijayakumar ${ }^{\mathrm{a}}$, Changchun $\mathrm{Yu}^{\mathrm{a}}$, and Gordon G. Wallace ${ }^{\mathrm{a}, *}$

${ }^{\mathrm{a}} \mathrm{ARC}$ Centre of Excellence for Electromaterials Science, Intelligent Polymer Research Institute, AIIM Facility, University of Wollongong, North Wollongong, NSW 2500, Australia.

${ }^{\mathrm{b}}$ Institute for Superconducting and Electronic Materials, AIIM Facility, University of Wollongong, North Wollongong, NSW 2500, Australia.

E-mail: caiyun@uow.edu.au (C. W.), gwallace@uow.edu.au (G. G. W.)

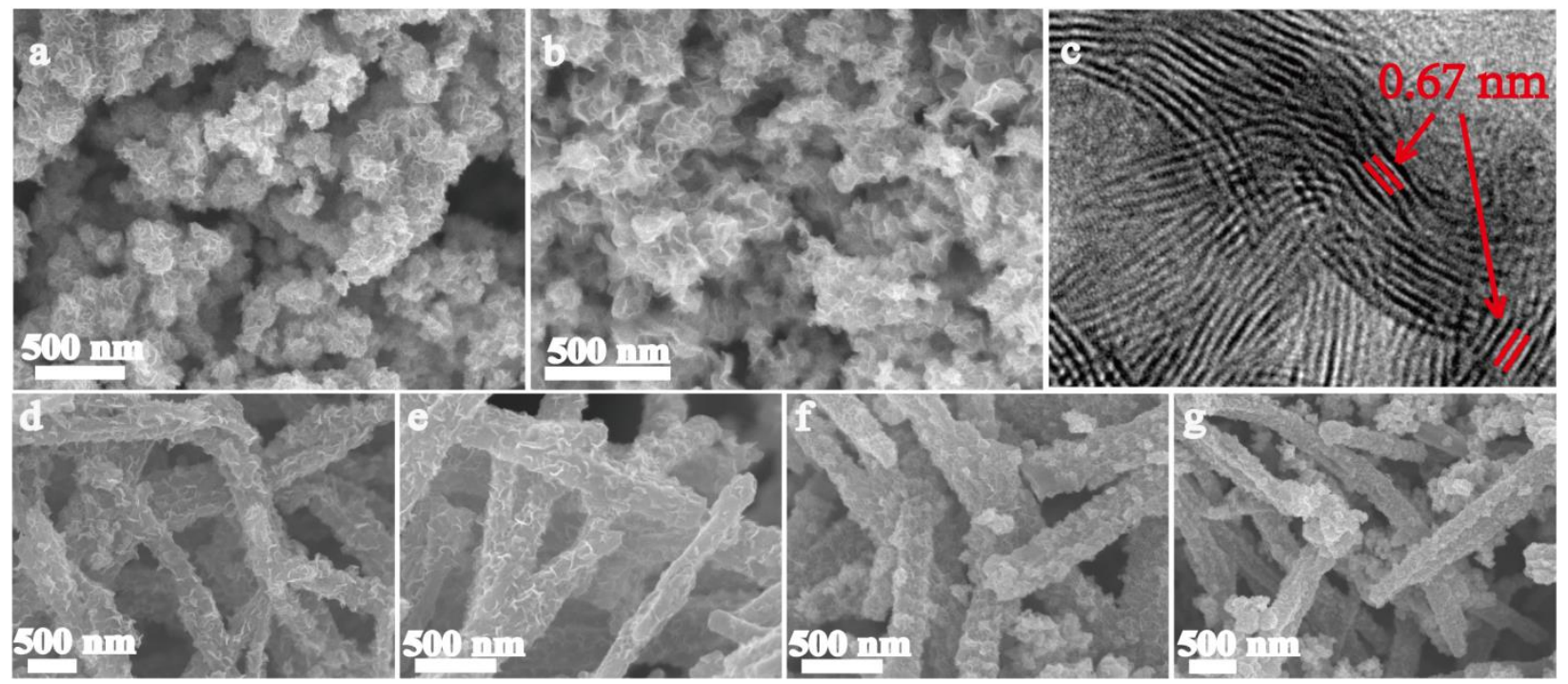


Figure S1. SEM images of $\mathrm{MoS}_{2}$ (a), annealed $\mathrm{MoS}_{2}$ (b), $1 \mathrm{MoS}_{2} / \mathrm{PPy}$ nanotubes (d), $1 \mathrm{MoS}_{2} / \mathrm{CNT}$ (e), $4 \mathrm{MoS}_{2} / \mathrm{PPy}$ nanotubes (f), and $4 \mathrm{MoS}_{2} / \mathrm{CNT}$ (g); HRTEM image of annealed $\mathrm{MoS}_{2}(\mathrm{c})$.
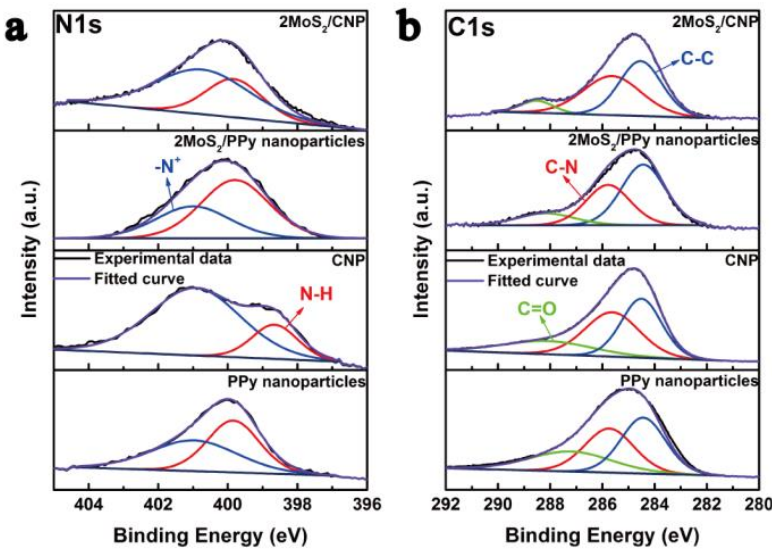
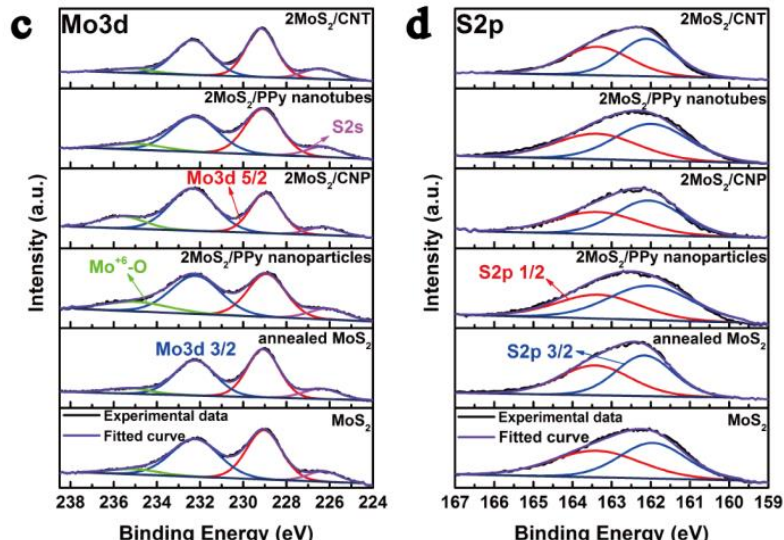

Figure S2. XPS N1s (a) and C1s (b) spectra of PPy nanoparticles, CNP, 2MoS $2 / \mathrm{PPy}$ nanoparticles and $2 \mathrm{MoS}_{2} / \mathrm{CNP}$ composites; XPS Mo3d (c) and S2p (d) spectra of $\mathrm{MoS}_{2}$, Annealed $\mathrm{MoS}_{2}, 2 \mathrm{MoS}_{2} / \mathrm{PPy}, 2 \mathrm{MoS}_{2} / \mathrm{CNT}$ and $2 \mathrm{MoS}_{2} / \mathrm{CNP}$ composites.

$\mathbf{a}$

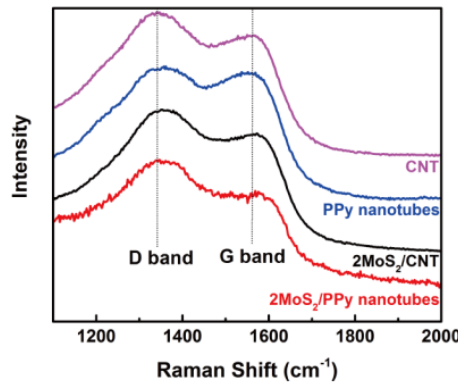

d

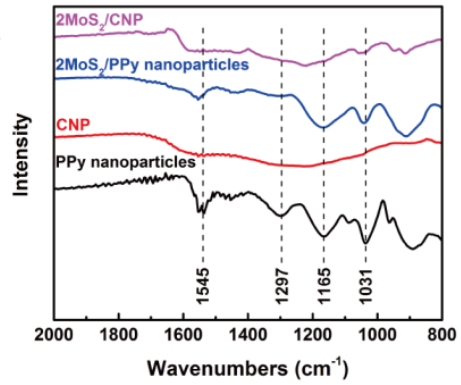

b
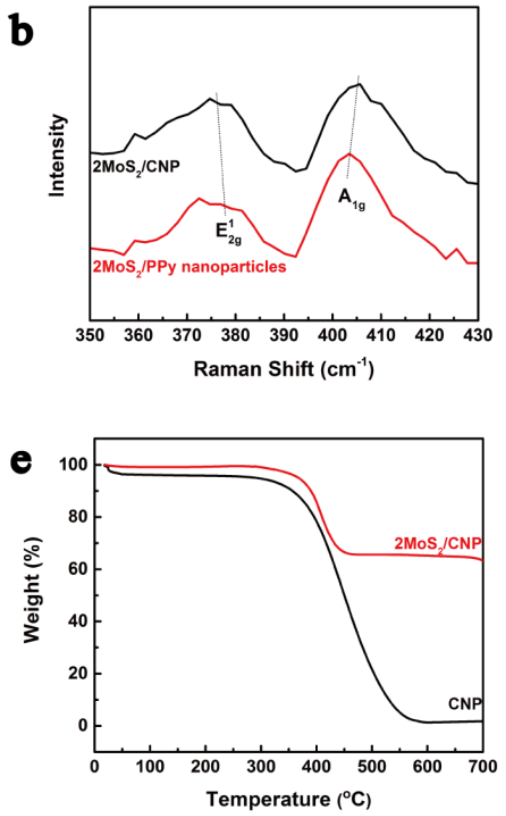

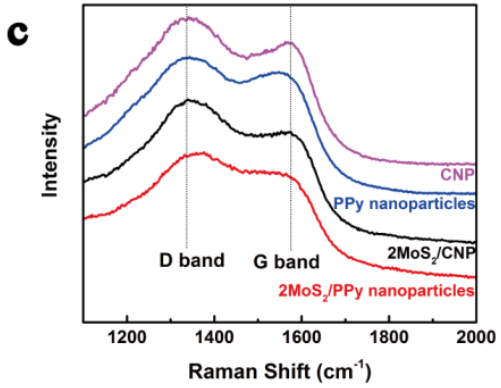

$\mathbf{f}$

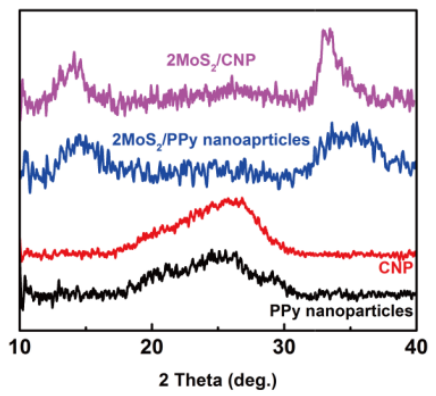


Figure S3. (a) Raman spectra of PPy nanotubes, CNT, $2 \mathrm{MoS}_{2} / \mathrm{PPy}$ nanotubes and $2 \mathrm{MoS}_{2} / \mathrm{CNT}$ composites; (b-c) Raman spectra of PPy nanoparticles, CNP, 2MoS $2 / \mathrm{PPy}$ nanoparticles and $2 \mathrm{MoS}_{2} / \mathrm{CNP}$ composites; FTIR spectra (d) and XRD curves (f) of PPy nanoparticles, CNP, $2 \mathrm{MoS}_{2} / \mathrm{PPy}$ nanoparticles and $2 \mathrm{MoS}_{2} / \mathrm{CNP}$ composites; (e) TGA curves of CNP and $2 \mathrm{MoS}_{2} / \mathrm{CNP}$ composite.

a

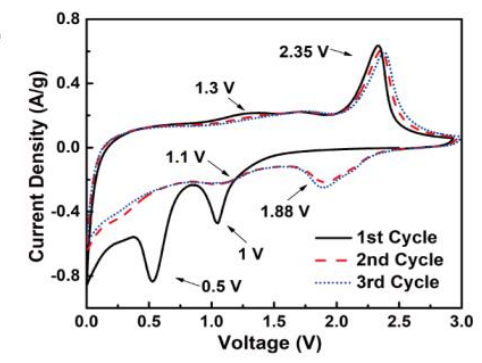

d

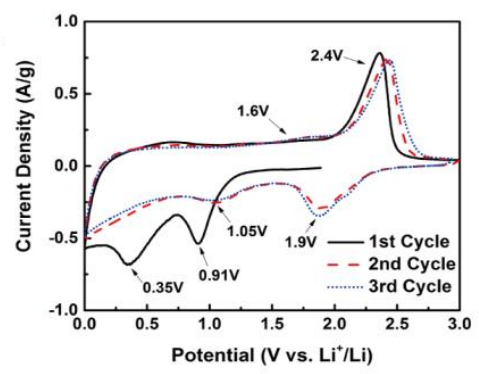

b
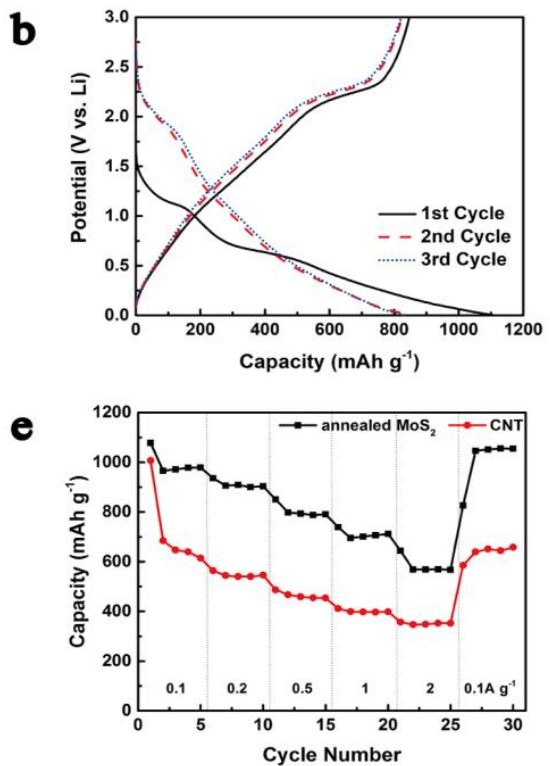

c
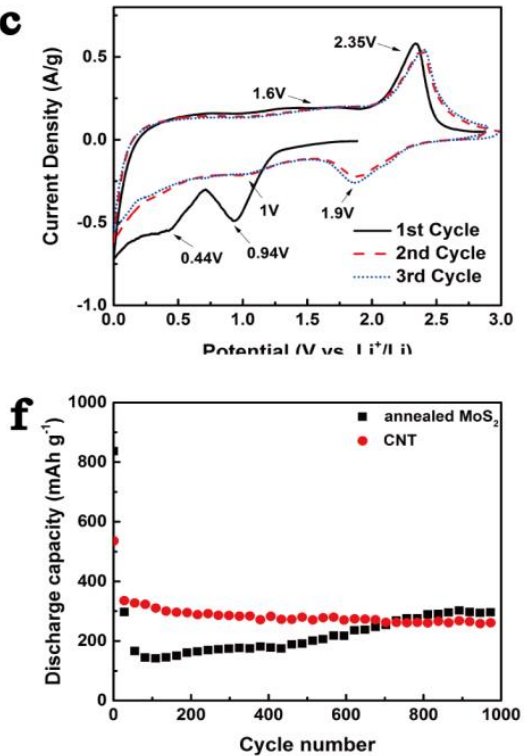

Figure S4. The first three cyclic voltammograms of $2 \mathrm{MoS}_{2} / \mathrm{CNP}$ (a), $1 \mathrm{MoS}_{2} / \mathrm{CNT}$ (c) and $4 \mathrm{MoS}_{2} / \mathrm{CNT}$ (d) composite at a scan rate of $0.2 \mathrm{mV} \mathrm{s}^{-1}$; (b) The first three discharge/charge curves of $2 \mathrm{MoS}_{2} / \mathrm{CNP}$ composite at a current density of $100 \mathrm{~mA} \mathrm{~g}^{-1}$ over a potential range of 0.005 to $3 \mathrm{~V}$; Rate capability (e) and cycling stability (f) of annealed $\mathrm{MoS}_{2}$ and CNT. 


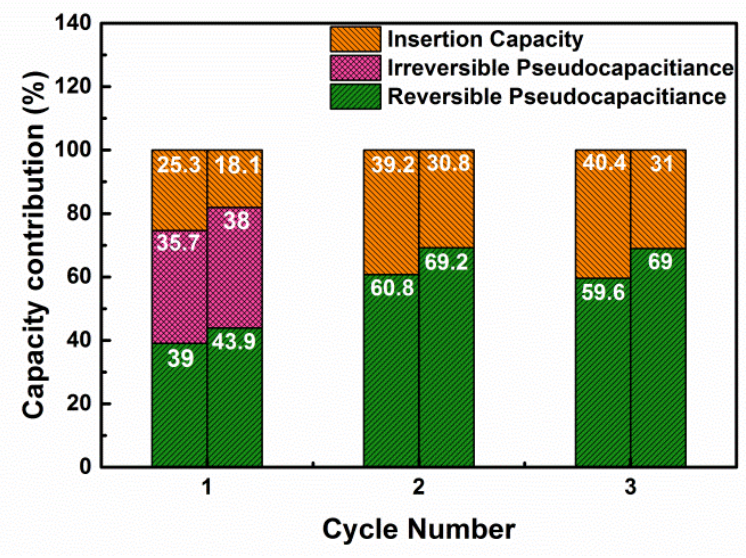

Figure S5. Bar chart displaying the capacity contributions of $2 \mathrm{MoS}_{2} / \mathrm{CNT}$ (left column) and $2 \mathrm{MoS}_{2} / \mathrm{CNP}$ (right column) in the first three discharge cyclic voltammograms scans.

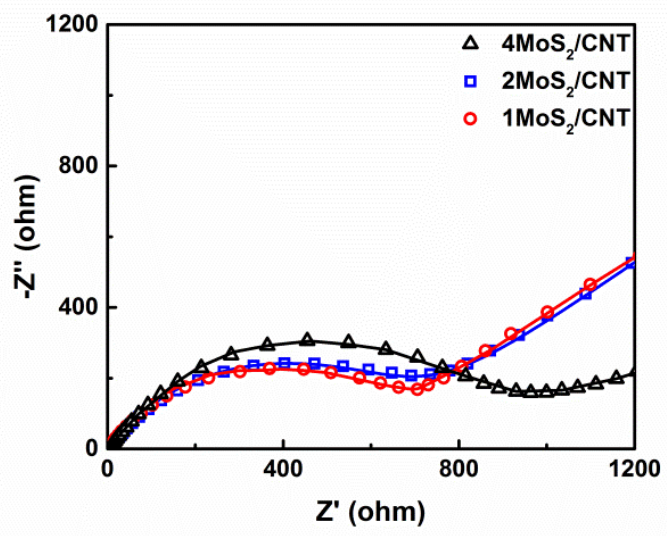

Figure S6 Nyquist plots (symbols) and fitting curves (lines) of fresh battery cells made at the open circuit potential over a frequency range of $100 \mathrm{kHz}$ to $10 \mathrm{mHz}$.

Table S1. Electrochemical performance of $2 \mathrm{MoS}_{2} / \mathrm{CNT}$ composite prepared in this study in comparison with the reported results for $\mathrm{MoS}_{2} /$ nitrogen-doped carbon composites 


\begin{tabular}{|c|c|c|c|}
\hline & $\begin{array}{l}\text { Capacity }\left(\mathrm{mAh} \mathrm{g}^{-1}\right) / \\
\text { current density }\left(\mathrm{A} \mathrm{g}^{-1}\right)\end{array}$ & $\begin{array}{c}\text { Capacity }\left(\mathrm{mAh} \mathrm{g}^{-1}\right) / \text { Cycle number } \\
\text { /Current density }\left(\mathrm{A} \mathrm{g}^{-1}\right)\end{array}$ & \\
\hline $2 \mathrm{MoS}_{2} / \mathrm{CNT}$ & $1232 / 0.1,947 / 2$ & $754 / 1000 / 1$ & This work \\
\hline $\begin{array}{l}\mathrm{MoS}_{2} / \text { nitrogen-containing } \\
\text { carbon/graphene hybrids }\end{array}$ & $1183 / 0.1,947 / 2$ & $1093 / 100 / 0.2$ & [1] \\
\hline $\begin{array}{c}\text { N-doped carbon } \\
\text { nanotube@ } \mathrm{MoS}_{2} \text { nanosheets }\end{array}$ & 1040.2/0.2, 651.2/1.6 & $645.8 / 200 / 1.6$ & [2] \\
\hline $\mathrm{C} @ \mathrm{MoS}_{2}$ nanoboxes & $1280 / 0.1,689 / 2$ & $952 / 200 / 0.4$ & [3] \\
\hline $\begin{array}{c}\mathrm{MoS}_{2} / \text { nitrogen-doped carbon } \\
\text { hybrid nanorods }\end{array}$ & $1100.6 / 0.1,926 / 2$ & $890 / 100 / 1$ & [4] \\
\hline $\begin{array}{l}\mathrm{MoS}_{2} / \text { Nitrogen-Doped } \\
\text { Graphene Nanosheets }\end{array}$ & $1021.2 / 0.1,850 / 1$ & $1285.3 / 50 / 0.1$ & [5] \\
\hline nitrogen-doped carbon@ $\mathrm{MoS}_{2}$ & $1010 / 0.15,645 / 1.5$ & $1055 / 100 / 0.15$ & [6] \\
\hline $\begin{array}{l}\text { carbon-coated } \mathrm{MoS}_{2} / \text { nitrogen- } \\
\text { doped graphene aerogel }\end{array}$ & $980 / 0.2,630 / 2$ & $900 / 500 / 0.2$ & [7] \\
\hline $\begin{array}{l}\text { Nitrogen and sulfur co-doped } \\
\text { graphene supported } \mathrm{MoS}_{2}\end{array}$ & $1100 / 0.15,860 / 1.5$ & $1010 / 50 / 0.15$ & [8] \\
\hline $\mathrm{MoS}_{2}$-PPY-rGO & $1085 / 0.2,600 / 2$ & $1070 / 400 / 0.2$ & [9] \\
\hline $\begin{array}{c}\text { core-shell } \\
\mathrm{C} @ \mathrm{MoS}_{2} \text { microspheres }\end{array}$ & $690 / 0.1,670 / 1$ & $652 / 100 / 0.1$ & [10] \\
\hline $\mathrm{MoS}_{2} / \mathrm{C}$ sample & $1042 / 0.1,511 / 1$ & $888.1 / 50 / 0.1$ & [11] \\
\hline $\mathrm{MoS}_{2} / \mathrm{C}$ hybrids & $967 / 0.2,353.5 / 1.6$ & $400 / 500 / 1.6$ & {$[12]$} \\
\hline $\begin{array}{l}\mathrm{MoS}_{2} / \mathrm{C} \text { flower-like } \\
\text { microspheres }\end{array}$ & $911.6 / 0.2,574.1 / 4$ & $916.6 / 400 / 0.2$ & [13] \\
\hline $\begin{array}{l}\mathrm{MoS}_{2} / \mathrm{N} \text {-doped carbon on } \\
\text { carbon microtubes }\end{array}$ & $1090 / 0.2,600 / 4$ & $1058 / 500 / 0.2,571 / 320 / 4$ & [14] \\
\hline
\end{tabular}

References:

[1] Z. Guo, Y. Zhong, Z. Xuan, C. Mao, F. Du, G. Li, Polypyrrole-assisted synthesis of roselike $\mathrm{MoS}_{2} /$ nitrogen-containing carbon/graphene hybrids and their robust lithium storage performances, RSC Adv. 5 (2015) 62624-62629.

[2] X. Zhao, G. Wang, X. Liu, X. Zheng, H. Wang, Ultrathin $\mathrm{MoS}_{2}$ with expanded interlayers supported on hierarchical polypyrrole-derived amorphous $\mathrm{N}$-doped carbon tubular structures for high-performance Li/Na-ion batteries, Nano Res. (2017), https://doi.org/10.1007/s12274-0171927-2.

[3] X.Y. Yu, H. Hu, Y. Wang, H. Chen, X.W. Lou, Ultrathin $\mathrm{MoS}_{2}$ nanosheets supported on Ndoped carbon nanoboxes with enhanced lithium storage and electrocatalytic properties, Angew. Chem. Int. Ed. 54 (2015) 7395-7398. 
[4] Q. Zhu, C. Zhao, Y. Bian, C. Mao, H. Peng, G. Li, K. Chen, $\mathrm{MoS}_{2} /$ nitrogen-doped carbon hybrid nanorods with expanded interlayer spacing as an advanced anode material for lithium ion batteries, Synth. Met. 235 (2018) 103-109.

[5] K. Chang, D. Geng, X. Li, J. Yang, Y. Tang, M. Cai, R. Li, X. Sun, Ultrathin $\mathrm{MoS}_{2} /$ nitrogendoped graphene nanosheets with highly reversible lithium storage, Adv. Energy Mater. 3 (2013) 839-844.

[6] D. Xie, X. Xia, Y. Wang, D. Wang, Y. Zhong, W. Tang, X. Wang, J. Tu, Nitrogen-doped carbon embedded $\mathrm{MoS}_{2}$ microspheres as advanced anodes for lithium-and sodium-ion batteries, Chem. Eur. J. 22 (2016) 11617-11623.

[7] D. Xie, W.J. Tang, X.H. Xia, D.H. Wang, D. Zhou, F. Shi, X.L. Wang, C.D. Gu, J.P. Tu, Integrated 3D porous $\mathrm{C}-\mathrm{MoS}_{2} /$ nitrogen-doped graphene electrode for high capacity and prolonged stability lithium storage, J. Power Sources 296 (2015) 392-399.

[8] Q. Liu, Z. Wu, Z. Ma, S. Dou, J. Wu, L. Tao, X. Wang, C. Ouyang, A. Shen, S. Wang, Onepot synthesis of nitrogen and sulfur co-doped graphene supported $\mathrm{MoS}_{2}$ as high performance anode materials for lithium-ion batteries, Electrochim. Acta 177 (2015) 298-303.

[9] D. Xie, D.H. Wang, W.J. Tang, X.H. Xia, Y.J. Zhang, X.L. Wang, C.D. Gu, J.P. Tu, Binderfree network-enabled $\mathrm{MoS}_{2}$-PPY-rGO ternary electrode for high capacity and excellent stability of lithium storage, J. Power Sources 307 (2016) 510-518.

[10] Z. Wan, J. Shao, J. Yun, H. Zheng, T. Gao, M. Shen, Q. Qu, H. Zheng, Core-shell structure of hierarchical quasi-hollow $\mathrm{MoS}_{2}$ microspheres encapsulated porous carbon as stable anode for Li-Ion batteries, Small 10 (2014) 4975-4981.

[11] L. Hu, Y. Ren, H. Yang, Q. Xu, Fabrication of 3D hierarchical $\mathrm{MoS}_{2} /$ Polyaniline and $\mathrm{MoS}_{2} / \mathrm{C}$ Architectures for lithium-lon battery applications, ACS Appl. Mater. Inter. 6 (2014) 14644-14652.

[12] H. Wang, D. Ren, Z. Zhu, P. Saha, H. Jiang, C. Li, Few-layer MoS ${ }_{2}$ nanosheets incorporated into hierarchical porous carbon for lithium-ion batteries, Chem. Eng. J. 288 (2016) 179-184.

[13] Q.Q. Xiong, Z.G. Ji, J. Controllable growth of $\mathrm{MoS}_{2} /$ C flower-like microspheres with enhanced electrochemical performance for lithium ion batteries, J. Alloys Compd. 673 (2016) 215-219. 
[14] D. Xie, X. Xia, W. Tang, Y. Zhong, Y. Wang, D. Wang, X. Wang, J. Tu, Novel carbon channels from loofah sponge for construction of metal sulfide/carbon composites with robust electrochemical energy storage, J. Mater. Chem. A 5 (2017) 7 578-7585. 